Prabhakaran, U, Beale, R and Godley, M

Analysis of scaffolds with connections containing looseness

Computers \& Structures, 2011, 89 (21-22). pp. 1944-1955.

10.1016/j.compstruc.2011.03.016

This version is available: http://radar.brookes.ac.uk/radar/preview/c3e3f204-b1dd-f528-1f49-7dc7b6eb7acc/1/

Available on RADAR: July 2013

Copyright $(\subset$ and Moral Rights are retained by the author(s) and/ or other copyright owners. A copy can be downloaded for personal non-commercial research or study, without prior permission or charge. This item cannot be reproduced or quoted extensively from without first obtaining permission in writing from the copyright holder(s). The content must not be changed in any way or sold commercially in any format or medium without the formal permission of the copyright holders.

This document is the author's final version of the journal article. Some differences between the published version and this version may remain and you are advised to consult the published version if you wish to cite from it. 


\title{
Analysis of scaffolds with connections containing looseness
}

\author{
U. Prabhakaran ${ }^{1}$, R.G. Beale ${ }^{2, *}$ and M.H.R. Godley ${ }^{1}$ \\ ${ }^{I}$ School of the Built Environment, Oxford Brookes University, Gipsy Lane Campus, Headington, Oxford, \\ $O X 3 O B P, U K$ \\ ${ }^{2}$ School of Technology, Oxford Brookes University, Wheatley Campus, Wheatley, Oxfordshire, OX33 \\ $1 H X, U K$ \\ *Corresponding author: rgbeale@brookes.ac.uk; (44) 1865483354
}

\begin{abstract}
This paper presents an algorithm to model scaffold behaviour and follow the full moment-rotation curve including nonlinear loading and unloading behaviour and including looseness. Different approximations to the moment-rotation curves are developed and applied to simple frames. The Federation Européene de la Manutention (FEM) approach gave the simplest reliable results. The models are applied to frames including looseness effects where it is shown that for sway frames looseness reduces the capacity significantly but for braced frames looseness has less effect. Design recommendations for analyses of scaffolds with connections exhibiting looseness are made.
\end{abstract}

Keywords: scaffold, second-order analysis, looseness, non-linear, stability function, semi-rigid.

\section{Introduction}

Steel scaffolds are extensively used to provide access and support to permanent works during different stages of their construction. These structures are generally slender and prone to fail by elastic instability. The elastic buckling load of a scaffold is strongly influenced by the stiffnesses of the connections, which exhibit semi-rigid deformation behaviour that can contribute substantially to the stability of the structure as well as to the distribution of member forces.

Traditional analyses of framed structures have assumed that the connections between uprights and beams, or between uprights and bases, are either rigid or pinned. In the past, analyses of structures containing semi-rigid joints have been concerned primarily with hot-rolled sections [1]. Joints in hot-rolled sections are made by means of bolts or welding and hence the stiffnesses of the connections are relatively large and the joint rotations relatively low compared with those occurring in scaffold structures. Scaffold connections have non-linear moment-rotation curves and due to the asymmetry of some of the connections scaffold joints often exhibit different behaviour under clockwise and anti-clockwise rotations. They frequently have very low stiffnesses including the possibility of looseness at the connection. The looseness contributes to the overall deflection of the structure under loads [2]. These joints often deform plastically at low loads and hence elastic unloading curves are not parallel to the initial moment-rotation curves. The joints in scaffold structures are often subjected to frequent loading and unloading, for example due to wind pressure/wind suction effects. Fig. 1 (taken from 
reference [3]) shows moment-rotation curves for typical right-angled connectors used in used in tube and fitting scaffolds. Fig. 2 shows sample beam-to-upright connections. The K2 connections shown in Fig 2(c) are part of a proprietary system developed by Interserve Industrial Services Ltd, UK. Samples of these connectors were recently tested by two of the authors $[3,4,5]$. In addition, due to the slender nature of scaffold structures, geometric non-linear interactions between the axial load and lateral deformations increase the complexity of the analysis.
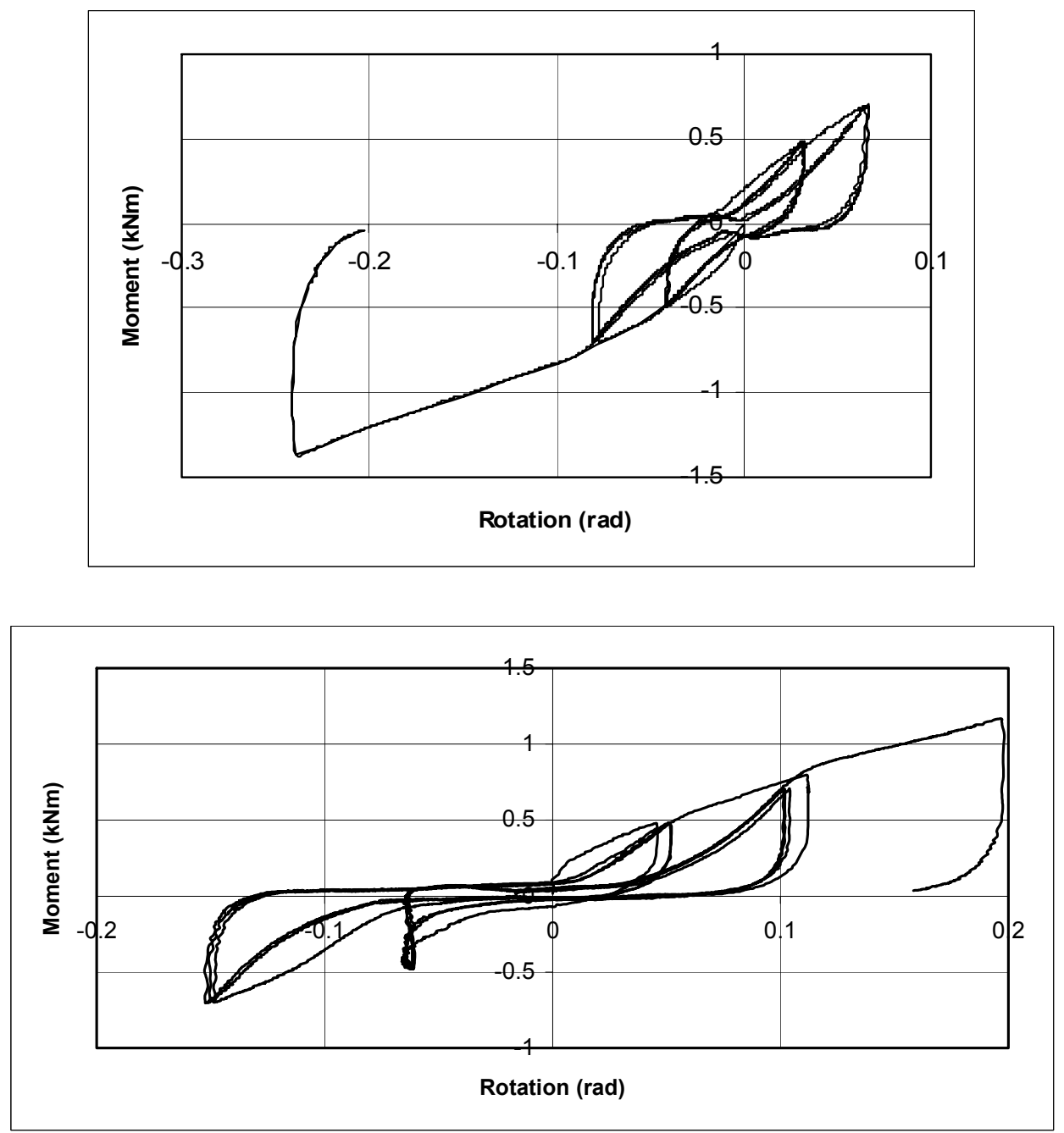

Fig. 1. Typical moment-rotation curves for tube and fitting right-angled connectors [3] 


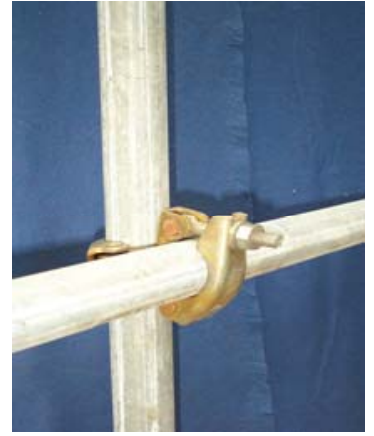

(a) right-angled coupler

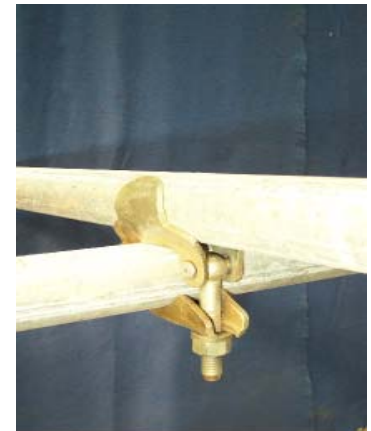

(b) putlog coupler

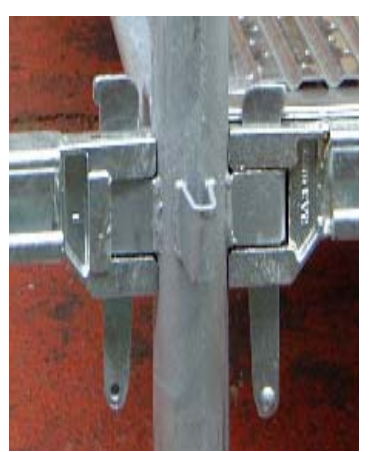

(c) K2 system proprietary coupler

Fig. 2 Typical connectors used in scaffold systems

The analyses in this paper are concerned with looseness in the beam-to-column connections. However, the numerical algorithm presented in the paper to model looseness can also be applied to any connection including connections between different column elements. When the columns, called standards in scaffolding, are joined splices are inserted. In the UK tube-and-fitting scaffolds the splices are applied externally to the tubes and in unpublished experiments conducted at the UK Building Research Establishment no looseness occurred when the standard deflects. In scaffolds where the splices are often inserted internally with spigots looseness does occur. However, research conducted at Oxford Brookes University when analysing tests conducted on a proprietary scaffold and performing numerical analyses $[2,6]$ showed that the ultimate load of the scaffolds analysed was not greatly affected when splices were included in the analysis.

The majority of the previous experimental and theoretical research [6-17] into scaffold structures has primarily concentrated on modelling the joints as elastic semi-rigid connections assuming a linear behaviour with the same clockwise and anti-clockwise rotational stiffnesses and unloading back down the same path as the loading path. For the purpose of design and analysis the moment-rotation curve is often assumed to be bilinear or multilinear and the same curve is used for both sagging and hogging moments. In some cases this assumption may be quite unrealistic. However, as can be seen from Fig. 1 [3] the assumption of linear behaviour is considerably in error even for common scaffold connections. The objective of this paper is to produce alternative models to conservatively estimate behaviour.

\section{Connection Behaviour}

\subsection{Experimental determination of connection properties}

The moment-rotation curves for scaffold connections are commonly found using a cantilever test. Fig. 3 shows the schematic of such a test together with a picture of a connection under test. Eurocode EN 12811-3:2002 [18] can be used to obtain a bilinear curve up to the maximum moment approximating the non-linear curve. Note that when the maximum moment is achieved the connections are often capable of large ductility and can sustain the maximum moment for large rotations as can clearly be seen in Fig. 1 and Fig. 3(b). Looseness is an additional feature of the moment curvature relations. The 
authors [4] have criticised the procedures in the Eurocode [18] as being ambiguous and have put forward alternatives. Eurocode EN 74-1:2005 [19] is a type test which sets minimum performance standards for tube and fitting connectors. The use of these minimum standards may give rise to conservative designs.

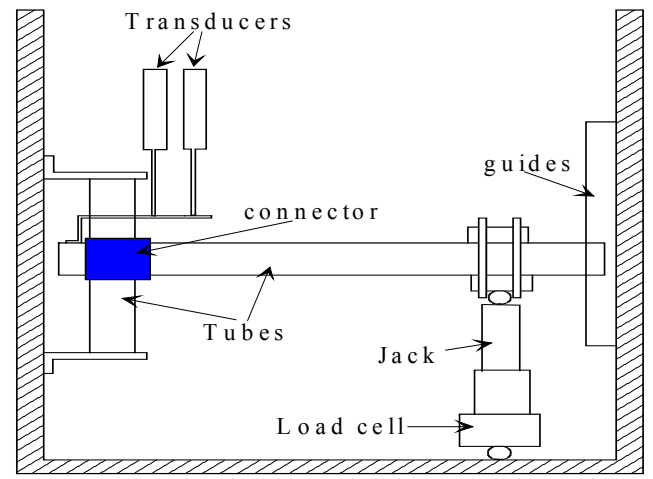

(a) Schematic of connection test

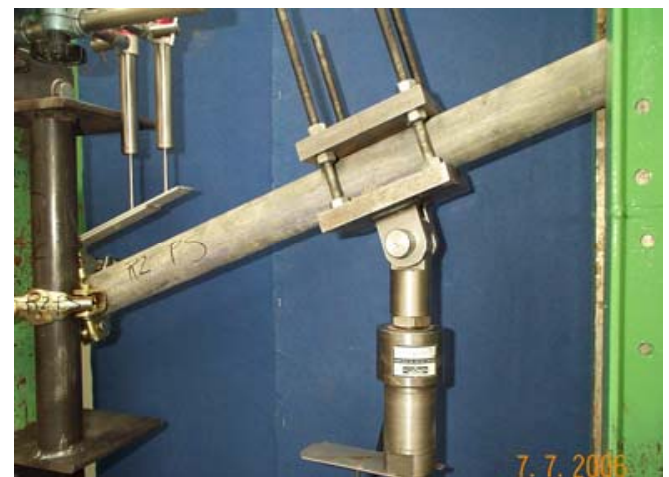

(b) right-angled coupler under test

Fig. 3. Cantilever test to determine moment-curvature curves

Note that the experiments shown in Fig. 1 and Fig. 3 were only conducted to determine the moment-rotation characteristics of the connections about an axis at right angles to beam-upright plane. For tube-and-fitting scaffolds the rotational stiffness of the connection about the other two axes is very low and in numerical modelling can be assumed to be pinned; hence looseness is not considered. For proprietary scaffolds the authors have produced very similar curves exhibiting very large nearly zero rotational stiffnesses to those shown in Fig. 1 for rotations about the other two axes. In these cases the cantilever test was not used but instead a frame constructed to determine the moment-rotation stiffnesses. Full details of the frame tests can be found in reference [2] or EN12810 [20]. From the authors experience of analysing scaffold systems there is limited three-dimensional interaction and the structures tend to fail in a direction either parallel or perpendicular to the façade to which the scaffold is attached [16]. Hence the discussion that follows is based on a two-dimensional model.

From test results [2-5] on different types of scaffold connections the following observations can be made about the moment-rotation $M-\theta$ curves of beam-to-upright connections:

- The moment-rotation behaviour of scaffold connections is nonlinear over the entire range of loading.

- At various points in the loading cycle rotational looseness is observed when the connections behave almost like a pin. At increased loads (both clockwise and anticlockwise), the stiffness of the joint decreases. The looseness of the connection increases as the amplitude of the loading cycle increases. In the tested connections, the rotation looseness was found to vary between 0.05 to 0.1 radians. 
- Joints undergo plastic deformation at low loads. Therefore, when a joint is unloaded the $M-\theta$ curve follows a different path which is not parallel to the original loading curve. However the unloading curve is found to be almost linear. When a connection is reloaded, the $M-\theta$ curve follows a path parallel to the unloading curve. The unloading stiffness is found to be greater than the loading stiffness of the connection as this is primarily elastic unloading without plastic deformation.

- The behaviour is generally not the same under positive (upward loading) and negative rotations (downward loading). The initial stiffness of the loading curve and the stiffness of the unloading curve vary significantly. This is due to the unsymmetrical nature of connections.

- Used connections exhibit similar behaviour to new connections.

\subsection{Connection Modelling}

\subsubsection{Formulation of the connection model}

Due to the complexity inherent in connections, the $M-\theta$ curve is mostly determined experimentally. For numerical analysis, since the behaviour of connections is represented by the instantaneous rotational stiffness of the joints, i.e. the slope of the moment-rotation curve, the property of the function used for the moment rotation curve is very important. In a scaffold structure, the nonlinear moment-rotation behaviour as well as rotational looseness needs to be considered when developing a connection model. In the following sections, three approaches to model the moment-rotation curve for scaffold structures are presented.

\subsubsection{Approximate curves obtained using regression analysis}

The most common method to obtain a moment-rotation curve is regression analysis. In this method, simple expressions are used to model the experimental data by adjusting the constant so as to give the best fit for the data. The moment-rotation curve thus obtained can be directly used in the analysis.

For the current research, a regression analysis of experiments conducted by Prabhakaran [5] was carried out using MathCAD. A polynomial function was found to give the best fit. The rotational looseness of the connection was ignored in the derivation of the polynomial function. Thus for the tested connections, the moment-rotation curve for loading was expressed using the following polynomial curve:

$$
\theta_{r}=\frac{M_{i}}{k_{\mathrm{o}}}\left[1.0+\left|\frac{M_{i}}{M_{u}}\right|\left(1.892\left|\frac{M_{i}}{M_{u}}\right|-0.876\right)\right]
$$

where $M_{i}$ is the instantaneous moment, $M_{u}$ the maximum moment, $k_{\mathrm{o}}$ the initial connection stiffness and $\theta_{r}$ the rotation. Eq. (1) was used for the loading components in 
both the positive and negative directions. Note that different $k_{\mathrm{o}}$ and $M_{u}$ are used for positive and negative rotations.

Eq. (1) is plotted against experimental results for specimens US3 and US6 (proprietary scaffold connections) in Fig. 4(a) and 4(b) respectively. In Fig. 4 a positive rotation is defined to occur after an upward load is applied the joint as shown in Fig 3 (b), for example. A negative rotation occurs after a downward load is applied to the joint. The full experimental results are found in Prabhakaran [5]. The instantaneous connection stiffness $k_{i}$ at any arbitrary rotation, $\theta_{r}$ is evaluated by differentiating the above expression.

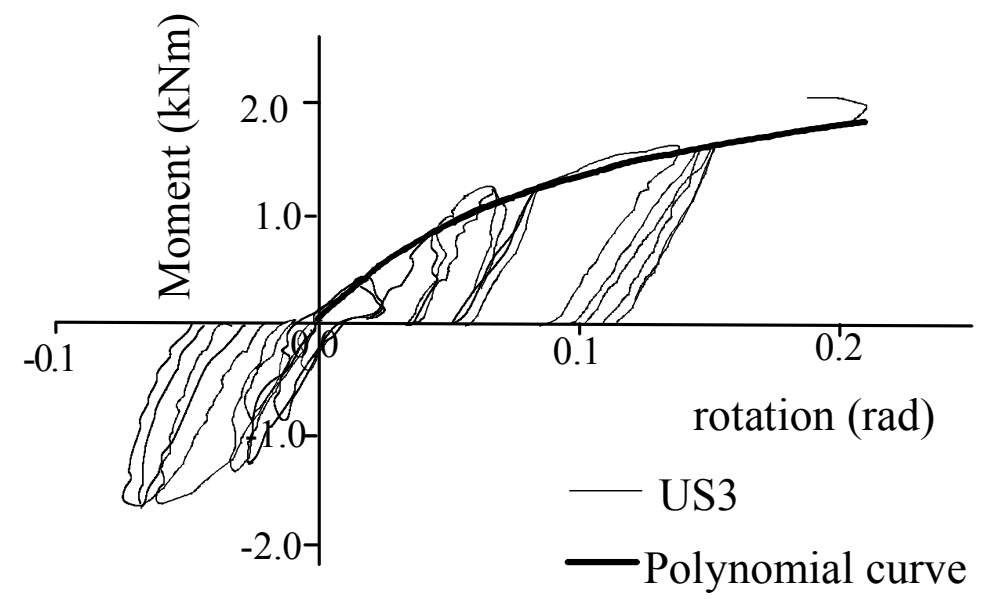

(a) Positive rotation curve (US3)

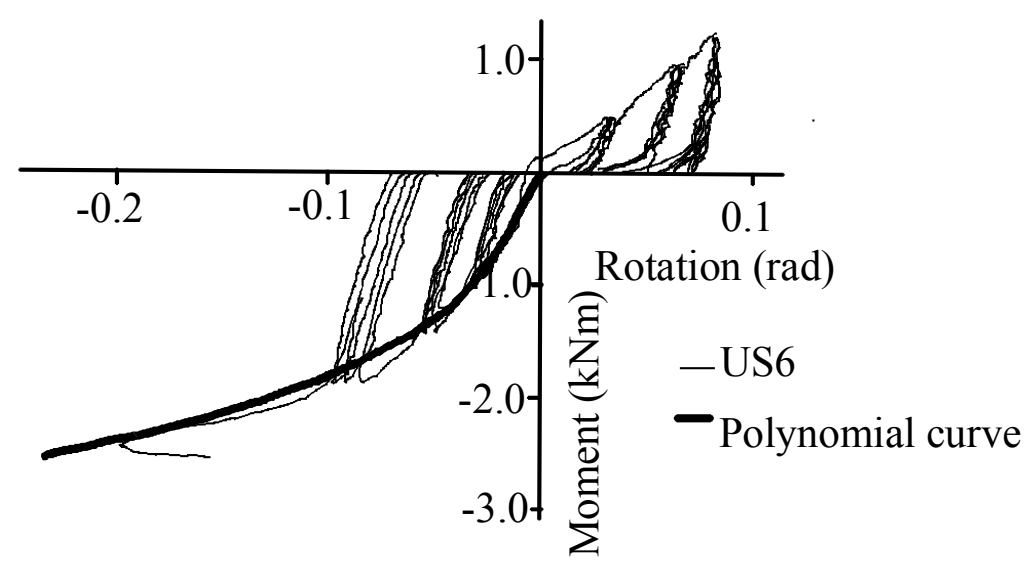

(b) Negative rotation curve (US6)

Fig.4. Comparison of regression curve against experimental data [5]

The initial loading stiffness for specimen US3 was found to be $23 \mathrm{kNm} / \mathrm{rad}$ and the unloading stiffness was found to be $45 \mathrm{kNm} / \mathrm{rad}$. For specimen US6, the initial loading stiffness was found to be $32 \mathrm{kNm} / \mathrm{rad}$ and the unloading stiffness was found to be 65 
$\mathrm{kNm} / \mathrm{rad}$. Note that as stated in Section 2.1 that in both tests the unloading stiffness is greater than the loading stiffnesses as unloading stiffnesses are primarily elastic.

Fig. 5 superimposes the loading and the unloading curves for specimen US3 and US6.

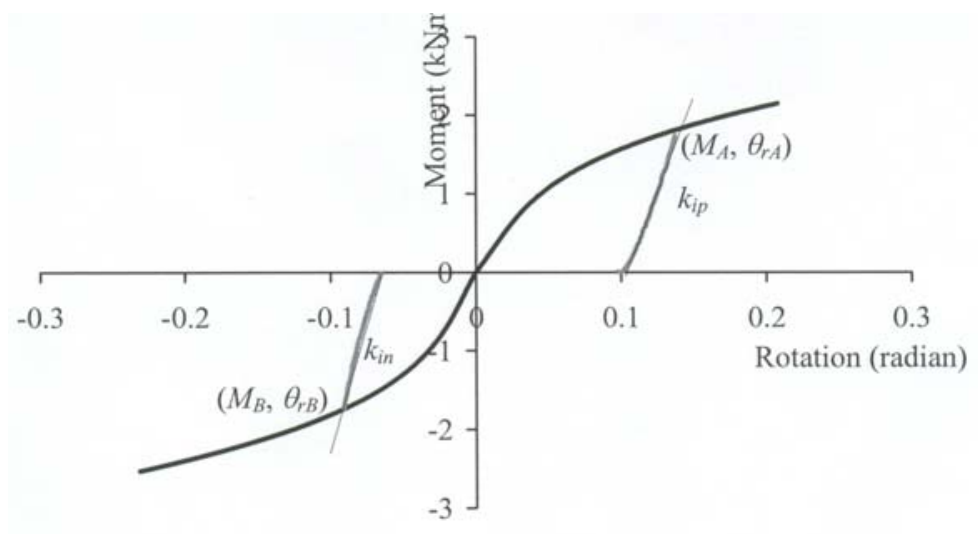

Fig. 5. Analytical model of the experimental data

Since the joint unloads approximately linearly, the unloading curve on the positive side can be expressed as a linear function of $M_{i}$ and $\theta_{r}$ :

$$
\theta_{r}=\theta_{r A}-\frac{1}{k_{i p}}\left(M_{A}-M_{i}\right)
$$

where $M_{A}$ is the moment at the start of unloading and $\theta_{r A}$ is the corresponding rotation. A similar line can be produced for unloading in the negative direction.

\subsubsection{The Federation Europeéne de la Manutention (FEM) approach}

Another approach to model the $M-\theta$ curve is that developed by the Federation Europeéne de la Manutention (FEM) for the design of pallet rack structures [21], which has been incorporated into EN 15512 [22]. Due to the similarity in the behaviour of scaffold and pallet rack structures, this method was considered to be an appropriate method to model the $M-\theta$ curve for scaffold connections.

In this approach the experimental curve is represented by a bilinear moment-rotation curve. The approximate curve is obtained by drawing a straight line through the origin in such a way that it divides the experimental $M-\theta$ curve into two equal areas below the chosen design moment for the connection. The resulting line has the same work as the original curve up to the maximum design moment. The slope of the straight line, $k_{t i}$ is the stiffness of the connection. A graphical representation is given in Fig. 6. The advantage of the Federation Europeéne de la Manutention approach is that it is easy to compute and can be used in standard finite element analysis programs. Abdel-Jaber et al $[23,24]$ conducted experimental results on portal frames made of pallet rack components and showed that this approach gave good estimates of the maximum 
moments occurring in frames but overestimated the deflections by about $10-15 \%$. Further analysis by Abdel-Jaber et al [25] showed that small changes in the assumed curves gave rise to significantly different calculated maximum moments and displacements of the frame, showing the sensitivity of these structures to small variations. The Federation Europeéne de la Manutention approach does not consider unloading and hence these were modelled using the same approach as for the regression analysis.

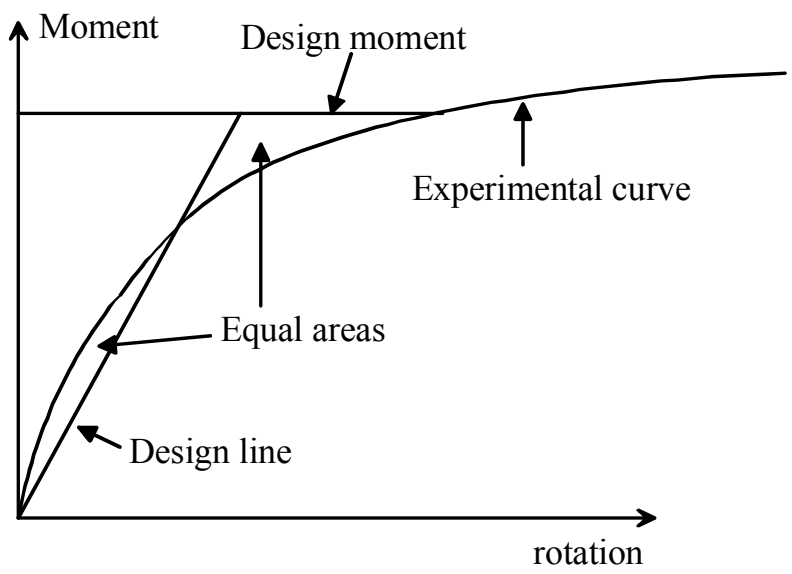

Fig.6. Schematic of the Federation Europeéne de la Manutention (FEM) approach

To account for the looseness in the down-aisle direction the Federation Europeéne de la Manutention (FEM) code [21] allows an out-of-plumb $\phi$ for the analysis. This provides for both the looseness $\left(\phi_{l}\right)$ of beam-to-upright connector and the frame imperfections $\left(\phi_{s}\right)$ during erection and is given by the following expression:

$$
\phi=\sqrt{\left(\frac{1}{2}+\frac{1}{n_{c}}\right)\left(\frac{1}{5}+\frac{1}{n_{s}}\right)}\left(2 \phi_{s}+\phi_{l}\right)
$$

where $\phi \leq\left(2 \phi_{s}+\phi_{l}\right)$ and $\phi \geq\left(\phi_{s}+0.5 \phi_{l}\right)$ and $\phi \geq 1 / 500$ is the maximum specified outof-plumb divided by the height. $n_{c}$ is the number if uprights in the frame in the downaisle direction and $n_{c}$ is the number of beam levels in the frame.

\subsubsection{The Eurocode approach}

The Eurocode EN12811-3 [18] method to model the $M-\theta$ curve requires the experimental curve to be modelled by fitting regression functions to the third cycle of a cyclic loading test. From these functions the characteristic strengths (called $R_{k, p o s}$ and $R_{k, n e g}$ ) are determined for clockwise and anti-clockwise rotations. A tri-linear momentrotation characteristic is derived. The first part is from the origin to the service moment $R_{k} / \gamma_{m} \gamma_{f}$, the second from there to the characteristic moment $R_{k}$ and finally a horizontal line at the characteristic moment. $\gamma_{m}$ and $\gamma_{f}$ are the material and resistance 
partial factors respectively. Provision is made to include looseness. A fully explained example of the Eurocode procedure may be found in reference [4] where recommendations are made about resolving ambiguities in the test procedure. In connections exhibiting looseness, the looseness is determined by extrapolating the moment-rotation curves back to the rotation axis. The difference between the two lines represents twice the looseness. A schematic of the Eurocode procedure is shown in Fig. 7.

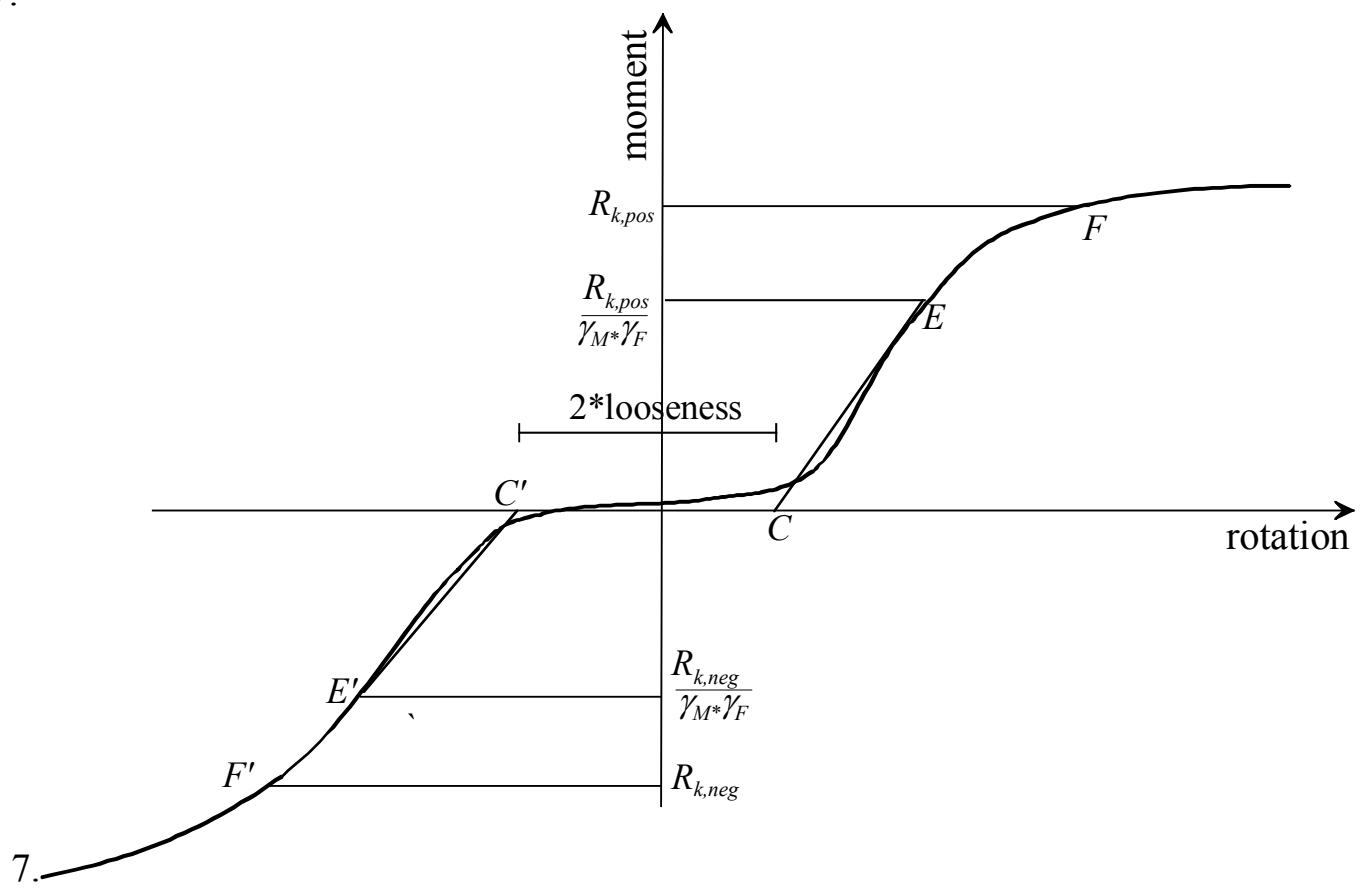

Fig.7. Evaluation of stiffnesses

\subsubsection{The Initial Stiffness and SEMA code approximations}

Two additional bilinear approximations were also considered for simplicity of using in programs. As neither procedure included unloading curves the unloading line Eq. (2) was used for these models.

- A bilinear curve based on the SEMA code [26] - The initial stiffness value was taken as the gradient of a line passing through the point of zero load and a point of the moment-rotation curve at half of the ultimate failure moment. At rotations in excess of the initial line meeting the maximum moment, the moment was kept constants. In the diagrams below this is called a bilinear curve.

- A bilinear curve based on the initial stiffness value followed by the maximum moment - The stiffness value here is also linear and is based on the initial stiffness value of the moment-rotation curve. This model was included as it common to the procedures adopted in many hot-rolled connections. In Fig. 13, Fig. 14, Fig. 16 and Fig. 18 below this is called the initial stiffness curve. 


\subsubsection{Numerical modelling}

In the current research the exact moment-rotation behaviour was modelled using the regression polynomial Eq. (1). The procedure described here assumed that the connections had different moment-rotation curves for clockwise and anticlockwise moments and exhibited rotational looseness. To model the unloading curves Eq. (2) was used. In the analysis procedure, whilst updating the nonlinear terms in the tangent stiffness matrix, connection moments are compared with those in the previous load step to determine whether the connection is in a state of loading or unloading. When the sign of the moment reverses, the appropriate curve is considered to determine the stiffness of the joint. A graphical representation of the algorithm is shown in Fig. 8.

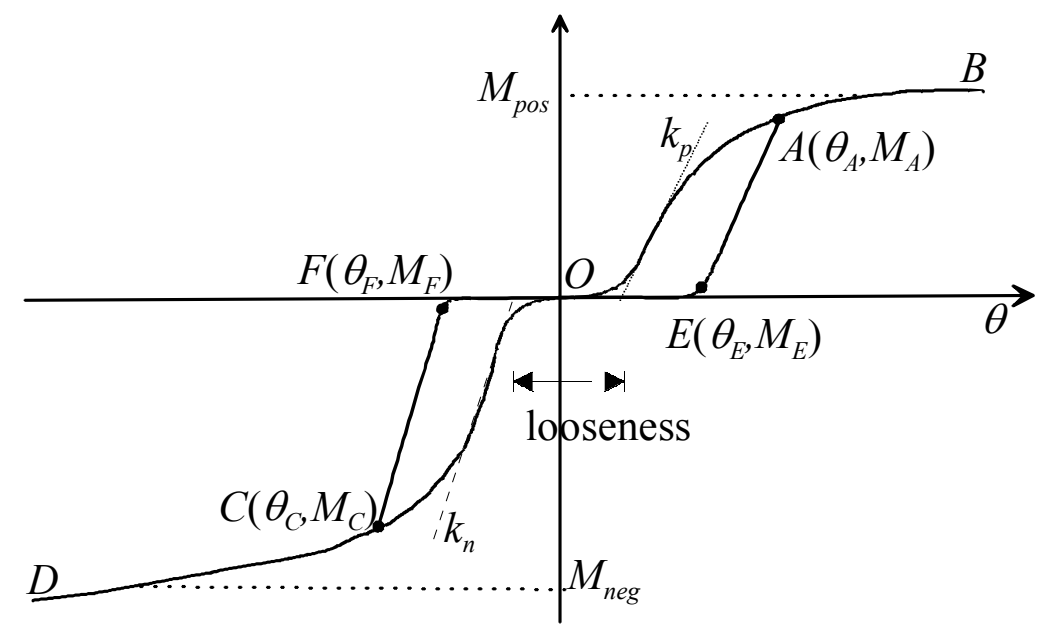

Fig.8. Computational moment-rotation curve

In the figure, $M_{u p}$ is the maximum positive moment and $k_{p}$ is the initial connection stiffness for positive rotation. The curve $O A B$ represents the corresponding virgin curve for monotonically increasing load and the curve $A E$ represents the unloading curve. $M_{\text {neg }}$ is the maximum negative moment and $k_{n}$ is the initial connection stiffness for negative rotation. Curve $O C D$ represents the corresponding loading curve and curve $C F$ represents the unloading curve. $l$ is the rotational looseness. At the beginning of the load cycle, the origin is set to $\left(\theta_{r}, 0\right)$ where $\theta_{r}$ is zero if no rotational looseness is present. The stiffness of the connection is taken as the initial stiffness of the connection i.e., $k_{i}=k_{p}$ or $k_{n}$. See Fig.8. For subsequent load increments the stiffness is obtained from the moment-rotation curve as described below. In the following paragraphs it is assumed that the joint is initially subjected to anticlockwise moment.

- When the joint is loaded, the stiffness is calculated from the curve $O A B$ given by

$$
M=f\left(\theta_{r}, M_{i}\right)
$$

where $M_{i}$ is the instantaneous moment and $\theta_{r}$ is the rotation. The loading curve is represented by an approximate function such as a polynomial function given in 
section 2.2.2. The instantaneous connection stiffness $k_{i}$ at any arbitrary rotation $\theta_{r}$ is evaluated by differentiating the above expression.

For subsequent load steps, the moment from the previous load increment is used to calculate the stiffness value. Within a load step the stiffness is kept constant for all the iterations. To determine the direction of loading, the moment at the beginning of a load step is compared with the moment obtained from the previous step. If the moment shows an increasing trend, the loading curve is used to determine the stiffness of the connection.

- When the joint unloads the stiffness is calculated from unloading curve $A E$. Thus we have from Eq. (2)

$$
\theta_{r}=\theta_{A}-\frac{1}{k_{i}}\left(M_{A}-M\right)
$$

In Fig.8, A refers to the point of unloading. The moment and rotation corresponding to point $A$ are stored for future reference. Since the unloading stiffness is much greater than the loading stiffness, a transition curve is used to provide a smooth transition from the loading curve $O A$ to the unloading curve $A E$.

- When the joint reaches $E$, the joint follows the flat curve $E O$. The moment and rotation corresponding to point $E$ are stored for future reference. A transition curve is used to provide a smooth transition from the unloading curve $A E$ to the curve $E O$.

- By the time the joint unloads, the connection has undergone a plastic rotation of $\theta_{E}$. Therefore reloading takes place parallel to $E A$ and when the moment reaches $M_{A}$, the virgin curve $A B$ is followed. Thus the rotation is given by

$$
\theta_{r}=\theta_{E}+\frac{1}{k_{i}}\left(M_{A}-M\right)
$$

- When the sign of the moment $M$ changes, the joint starts loading in the reverse direction, hence the loading curve $O C D$ is used for stiffness calculation. When the joint unloads, path $C F$ is followed. In Fig.8, $C$ refers to the point of unloading. The moment and rotation corresponding to point $C$ are stored for future reference. The joint unloads along the $C F$ curve followed by the $F O$ curve.

\subsubsection{Validation}

In the absence of test results on scaffold frames, the proposed algorithm was validated using a theoretical cantilever model shown in Fig. 9. The properties of the members were: Modulus of Elasticity, $\mathrm{E}=2.09 * 10^{8} \mathrm{~N} / \mathrm{m}^{2}$, area $=0.000280 \mathrm{~m}^{2}$ and moment of inertia $=0.7 * 10^{-7} \mathrm{~m}^{4}$. 


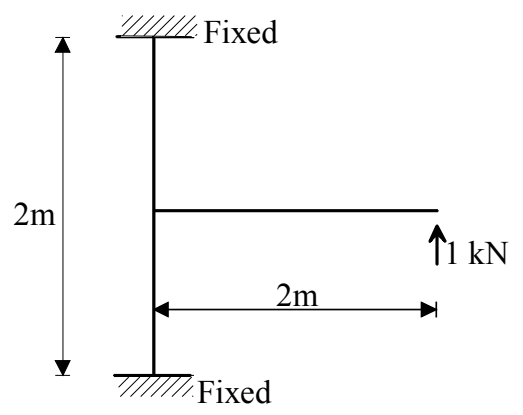

Fig.9. Cantilever model

The connection behaviour between the upright and the beam was modelled using the polynomial curves given in Fig. 8. The accuracy of the procedure was verified using simple hand calculations. Geometric nonlinearity was not considered for the analysis. At the free end a vertical load was applied in $1 \mathrm{kN}$ increments. Fig. 10(a) shows the moment-rotation curve obtained from the analysis. The model was also analysed for an initial rotational looseness of \pm 0.04 radians. Fig. 10(b) shows the moment-rotation curve obtained from the analysis. From Fig. 10 it can be seen that the loading and unloading behaviour of the joint can be accurately modelled using the proposed algorithm. The procedure was incorporated in the nonlinear analysis program to study the behaviour of scaffold frames.

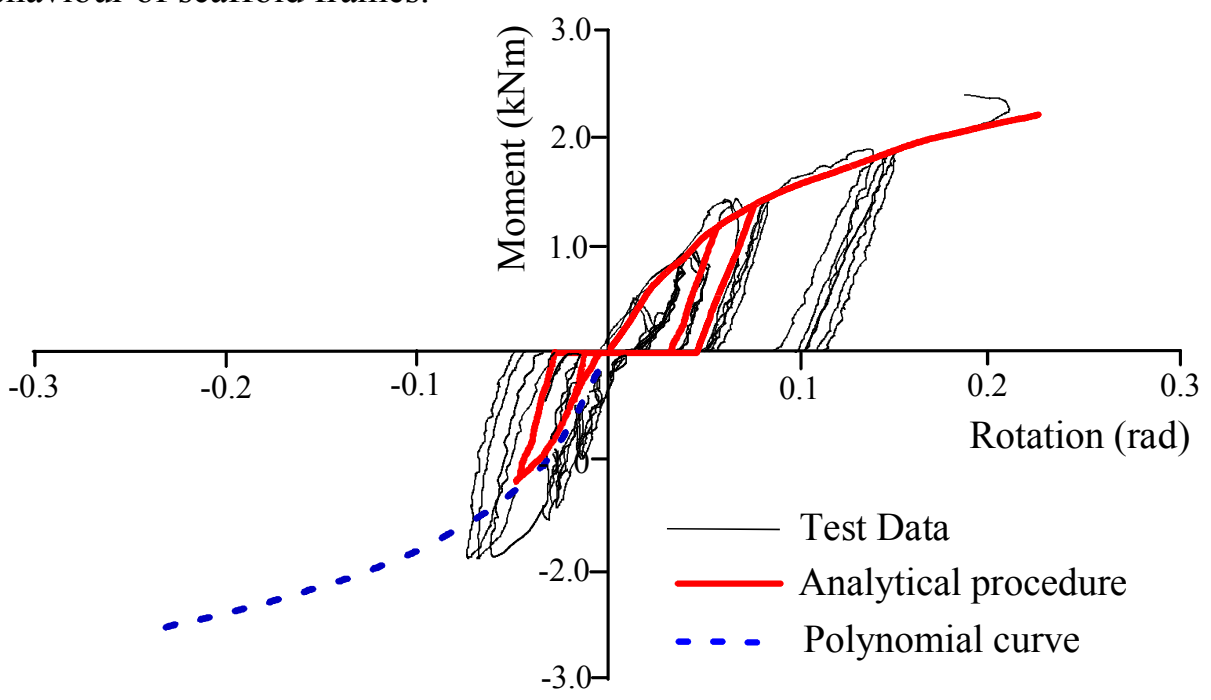

(a) without looseness

Fig. 10. Moment-rotation curves from cantilever model 


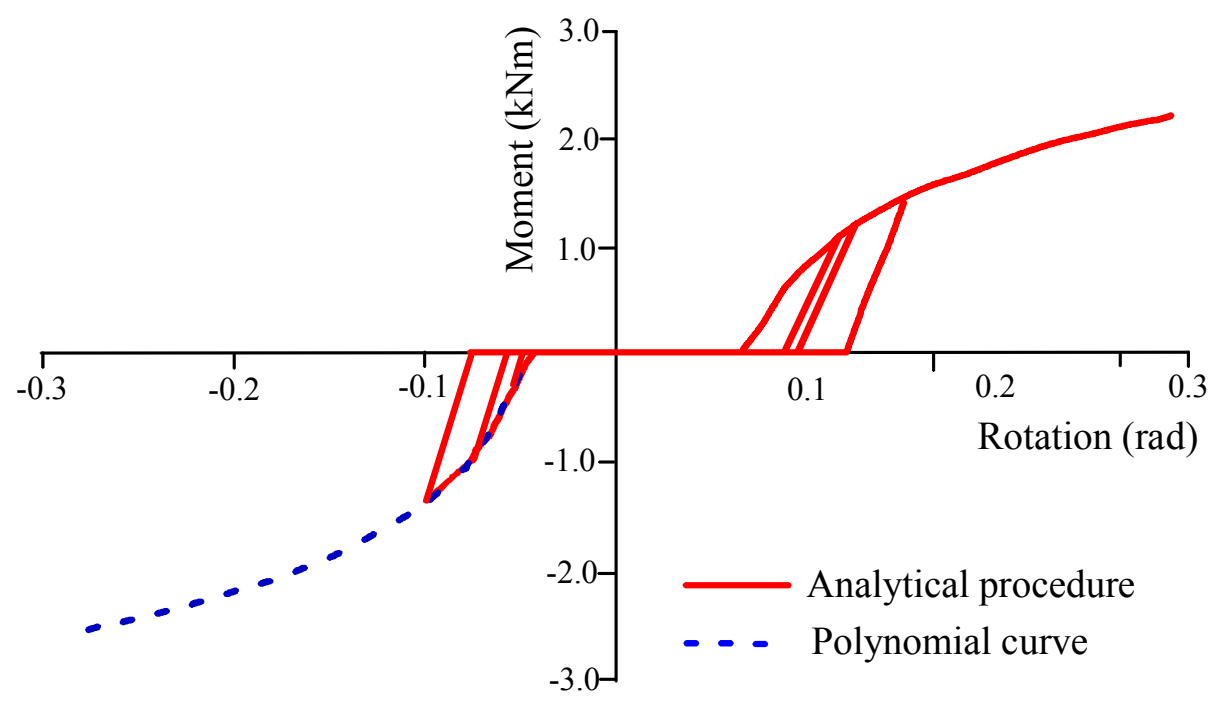

(b) with looseness

Fig. 10. Moment-rotation curves from cantilever model (continued)

\subsubsection{Connection Models}

Fig. 11 shows an experimental moment-rotation curve taken from Reference [3] together with the different approximation models considered. Table 1 presents the mathematical formulation of the various models.

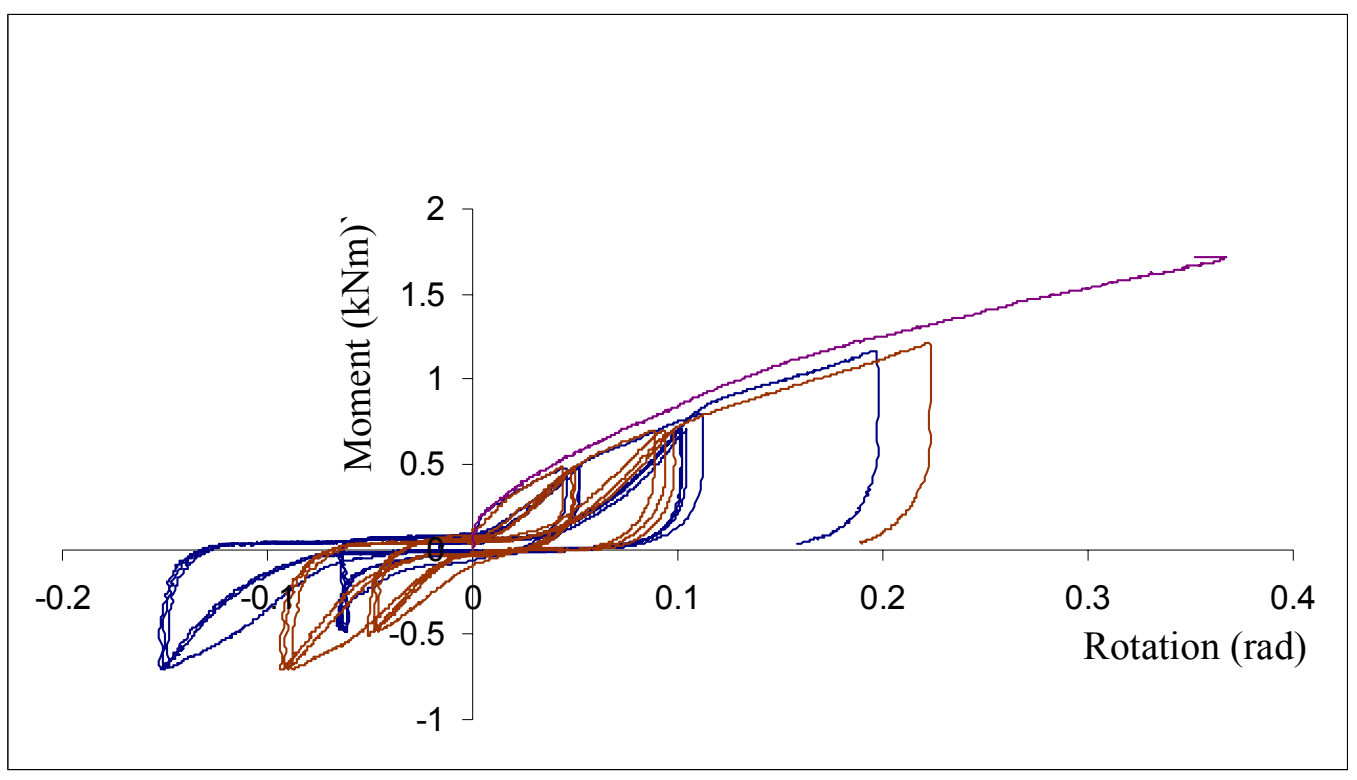

(a) Experimental curve

Fig. 11. Moment-rotation curve for a right-angled coupler 


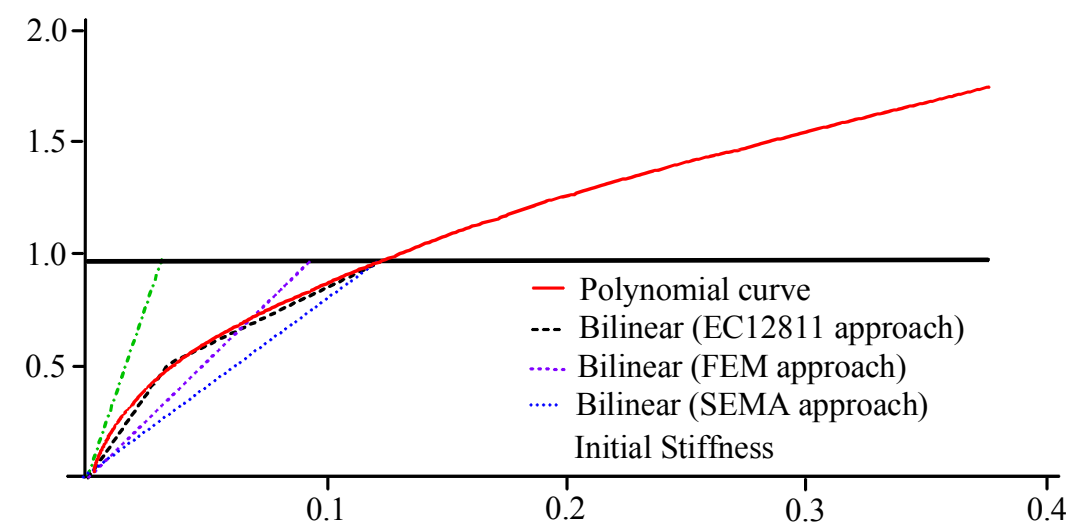

(b) Theoretical models

Fig. 11. Moment-rotation curve for a right-angled coupler (continued)

The horizontal line drawn in Fig. 11(b) is the characteristic strength predicted from the Eurocode [18]. This was the maximum rotational strength allowed in the computational models. The initial stiffness model assumes that the connection maintains its initial rotational stiffness until reaching its maximum allowed moment. The three bilinear stiffness models $(3,4,5)$ join the origin to the point where the moment-rotation curve reaches its characteristic strength and then are horizontal. The Eurocode (model 2) being tri-linear has two straight lines before the horizontal component at the characteristic strength.

\section{Table 1: Connection Models}

\section{Model Model Equations \\ No. Name}

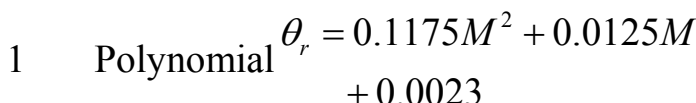

$$
M=0.97
$$

2 Eurocode

$$
\begin{aligned}
& M=15.383 \theta_{r} \\
& M=4.915 \theta_{r}+0.359 \\
& M=0.97
\end{aligned}
$$

3 FEM

$$
\begin{aligned}
M & =10.65 \theta_{r} \\
M & =0.97
\end{aligned}
$$

4

$\begin{array}{ll}\text { Bilinear } & M=7.82 \theta_{r} \\ \text { Curve } & M=0.97\end{array}$

\section{Rotation (Radians)}

$$
\begin{array}{lr}
0 \leq \theta_{r}<0.124 & 0 \leq M \leq 0.97 \\
0.124<\theta_{r} & M=0.97
\end{array}
$$

$0 \leq \theta_{r}<0.0343$

$$
0 \leq M \leq 0.527
$$$$
0.0343 \leq \theta_{r} \leq 0.124
$$

$0.124<\theta_{r}$

\section{(kNm)}

$$
\begin{aligned}
0.527 & \leq M \leq 0.97 \\
M & =0.97
\end{aligned}
$$

$0 \leq M \leq 0.97$

$M=0.97$

$0.091 \leq \theta_{r}$

$0 \leq M \leq 0.97$

$0 \leq \theta_{r}<0.0124$
$M=0.97$
$0.124<\theta_{r}$

(SEMA) 

5 Initial $\quad M=32.0 \theta_{r}$
$0 \leq \theta_{r}<0.0303$
$0 \leq M \leq 0.97$
stiffness
$M=0.97$
$0.0303 \leq \theta_{r}$
$M=0.97$
$6 \quad$ Unloading $M=65 \theta_{r}$
$M \geq 0.01$
curve
$M=1.0 \theta_{r}$
$0 \leq M \leq 0.01$

\section{Example frames}

\subsection{One bay sway frame}

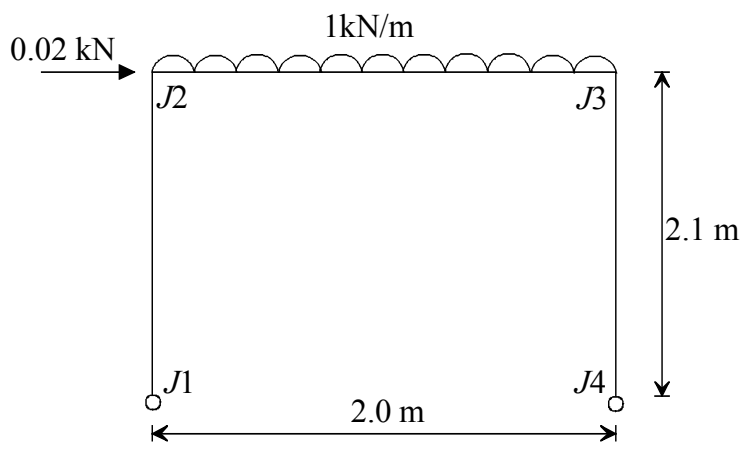

Fig.12. Simple sway frame

The pin ended sway frame shown in Fig.12 was analysed using the models in Section 2.2.8. The geometric $P-\Delta$ and corrections due to flexural shortening were included in the analysis. The Young's Modulus of Elasticity for the columns and the beam was taken to be $2.09 * 10^{8} \mathrm{kN} / \mathrm{m}^{2}$. The area of each column and beam was $0.557 * 10^{-6} \mathrm{~m}^{2}$. The moment of inertia of the columns and beams was $0.138^{*} 10^{-12} \mathrm{~m}^{4}$. For all cases the same bilinear unloading curve was used. The loads were increased proportionally until failure occurred. Under the loading the moment in joint $J 2$ always increased to a maximum before unloading. Depending upon the moment-curvature model the moment in joint $J 3$ sometimes also unloaded. Fig. 13 shows the moment and displacement behaviour of the joints. 


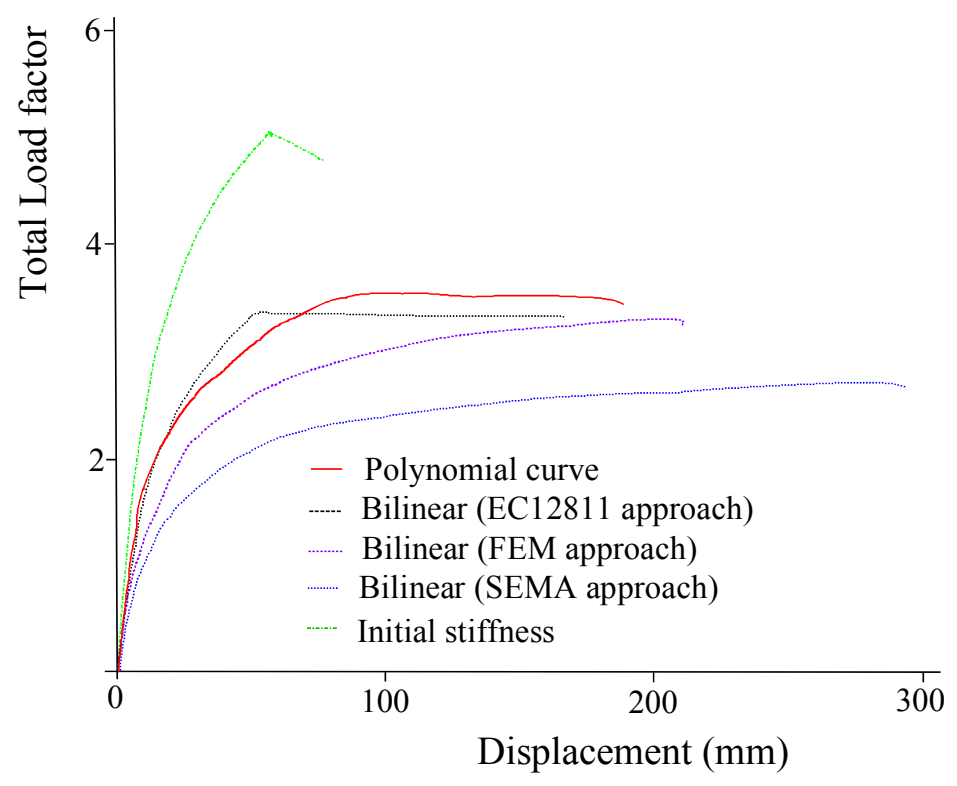

(a) Load- horizontal displacement curve of joint $J 2$

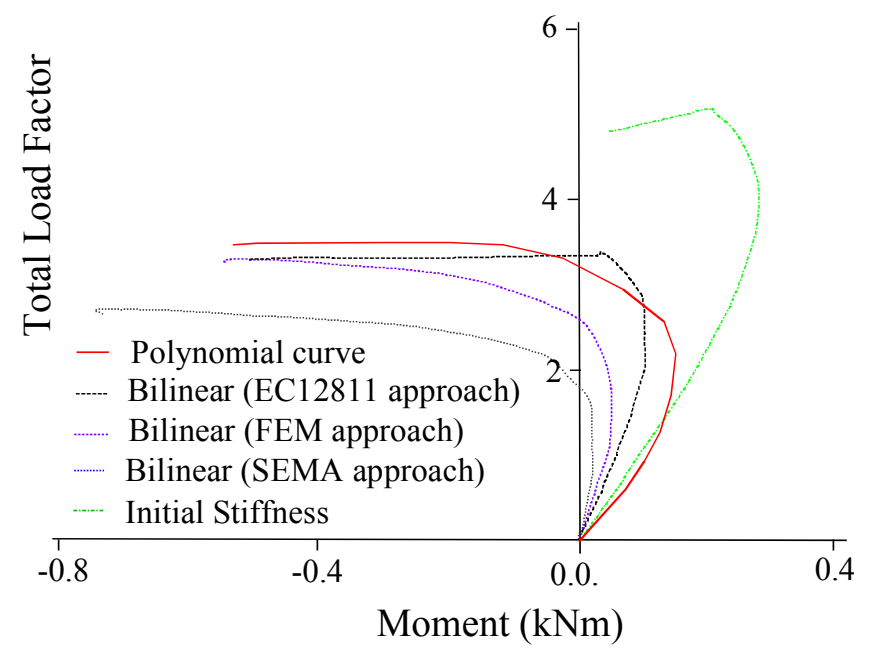

(b) Load-moment at joint $J 2$

Fig. 13. Load against displacement and moments for frame 1 


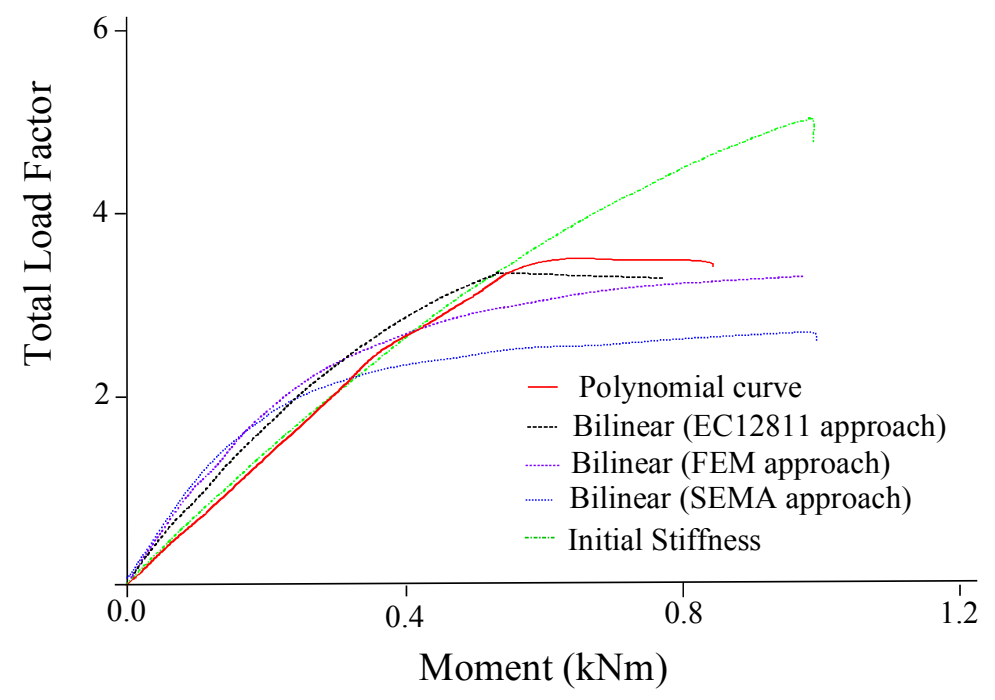

(c) Load-moment at joint $J 3$

Fig. 13. Load against displacement and moments for frame 1 (continued)

To investigate the influence of unloading stiffnesses on the maximum load two cases were considered: Case 1 - the unloading stiffness was taken to be the same as the loading stiffness. Case 2 - the unloading stiffness was modelled using the bilinear approximation (model 6) given in Table 1. The maximum moments and deflections predicted by the models are given in Table 2 with corresponding plots of load against displacement and moment given in Fig. 14. Note that the bilinear unloading model was not used for models 4 and 5 in Table 2.

Table 2: Maximum load and horizontal displacement

\begin{tabular}{|c|c|c|c|c|c|}
\hline $\begin{array}{l}\text { Model } \\
\text { No. }\end{array}$ & $\begin{array}{l}\text { Connection } \\
\text { Model }\end{array}$ & $\begin{array}{l}\text { Failure } \\
\text { Load } \\
(\text { case 1) } \\
(\mathbf{k N})\end{array}$ & $\begin{array}{l}\text { Displacement } \\
\text { at max load } \\
(\text { case 1) } \\
(\text { mm) }\end{array}$ & $\begin{array}{l}\text { Failure } \\
\text { Load } \\
\text { (case 2) } \\
(\mathbf{k N})\end{array}$ & $\begin{array}{l}\text { Displacement } \\
\text { at max load } \\
(\text { case } 2) \\
(\text { mm) }\end{array}$ \\
\hline 1 & Polynomial Curve & 3.52 & 105.9 & 3.25 & 119.3 \\
\hline 2 & Eurocode & 3.35 & 53.2 & 3.51 & 56.5 \\
\hline 3 & FEM & 3.31 & 204.1 & 3.22 & 205.4 \\
\hline 4 & Bilinear Curve & 2.69 & 289.6 & & \\
\hline 5 & Initial Stiffness & 5.05 & 56.7 & & \\
\hline
\end{tabular}




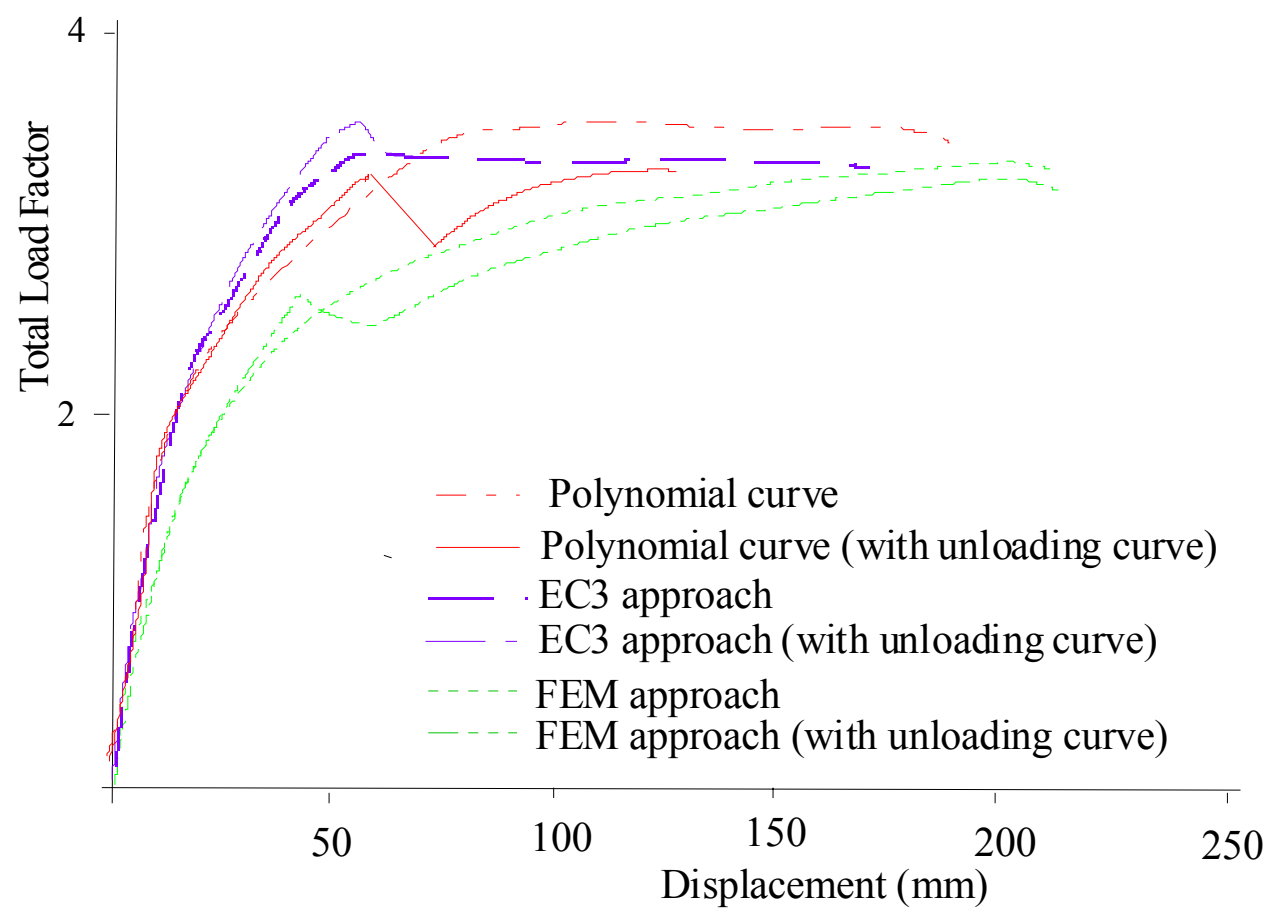

(a) Load- horizontal displacement curve of joint $J 2$

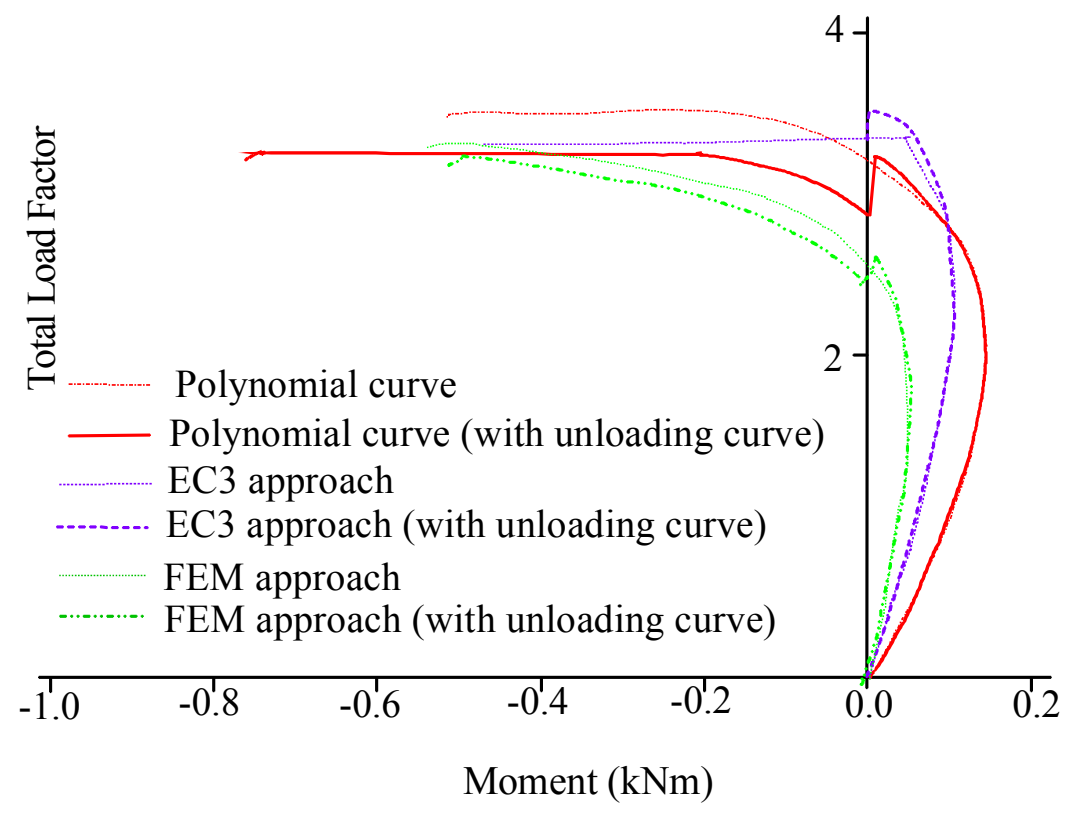

(b) Load-moment at joint $J 2$

Fig. 14. Effects of unloading curves on load-displacement and load-moment curves 


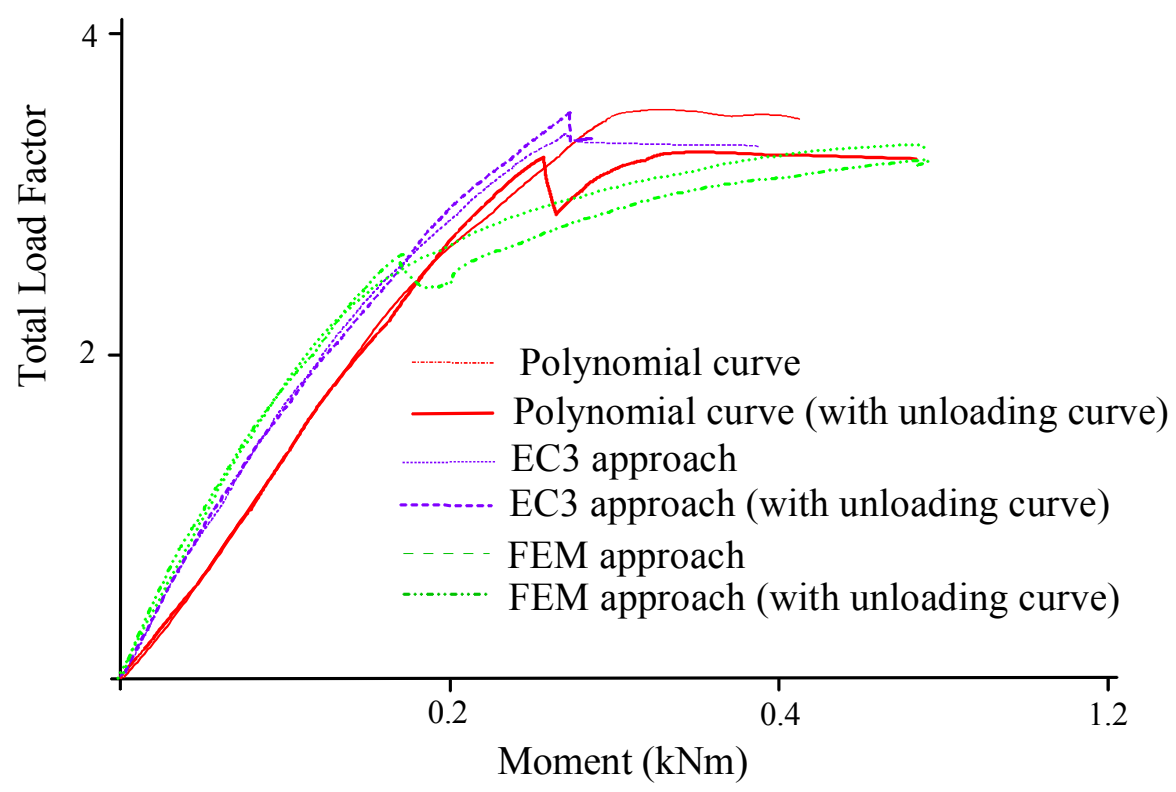

(c) Load-moment at joint $J 3$

Fig. 14. Effects of unloading curves on load-displacement and load-moment curves (continued)

From the resulting curves it can be seen that the maximum predicted load of the frame is given by the initial stiffness model. This result is likely to be highly unconservative of true behaviour as the assumption inherent in this approximation is that the scaffold does not deflect significantly before failure. If deflection and rotation of the joint occur then the rotational stiffness from this model is greatly in excess of that in the true structure.

The polynomial curve and the trilinear Eurocode yield similar results for both moments and deflections. However the bilinear stiffness curve predicts very large deflections which would exceed allowable values bearing in mind the size of the frame. The Federation Europeéne de la Manutention approach conservatively predicts the maximum moment but for this frame produces deflection calculations which possibly underestimate true deflections in contrast to the results from the experiments on pallet racks [23-24]. Applying the procedures in Section 2.2.6 to the pallet rack frame studied by Abdel-Jaber et al [25] showed that the results found for the sway frame matched the limited experimental data available [23]. From these results it was decided to remove the initial stiffness approximation and the bilinear stiffness approximation from the study when looseness was concerned.

In order to further investigate the effects of looseness, instead of only including it on the unloading sequence the frame was reanalysed using the polynomial model and putting an initial rotation stiffness of \pm 0.01 radian in the joint as seen in Fig. 15 . 


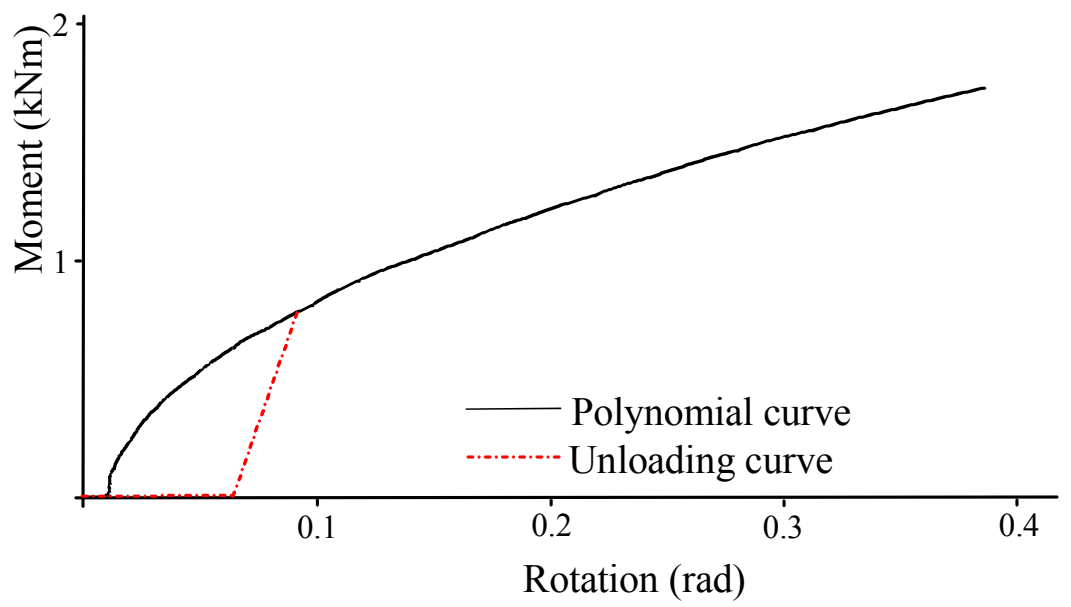

Fig.15. Connection model with looseness

The results of the analysis are shown in Fig. 16.

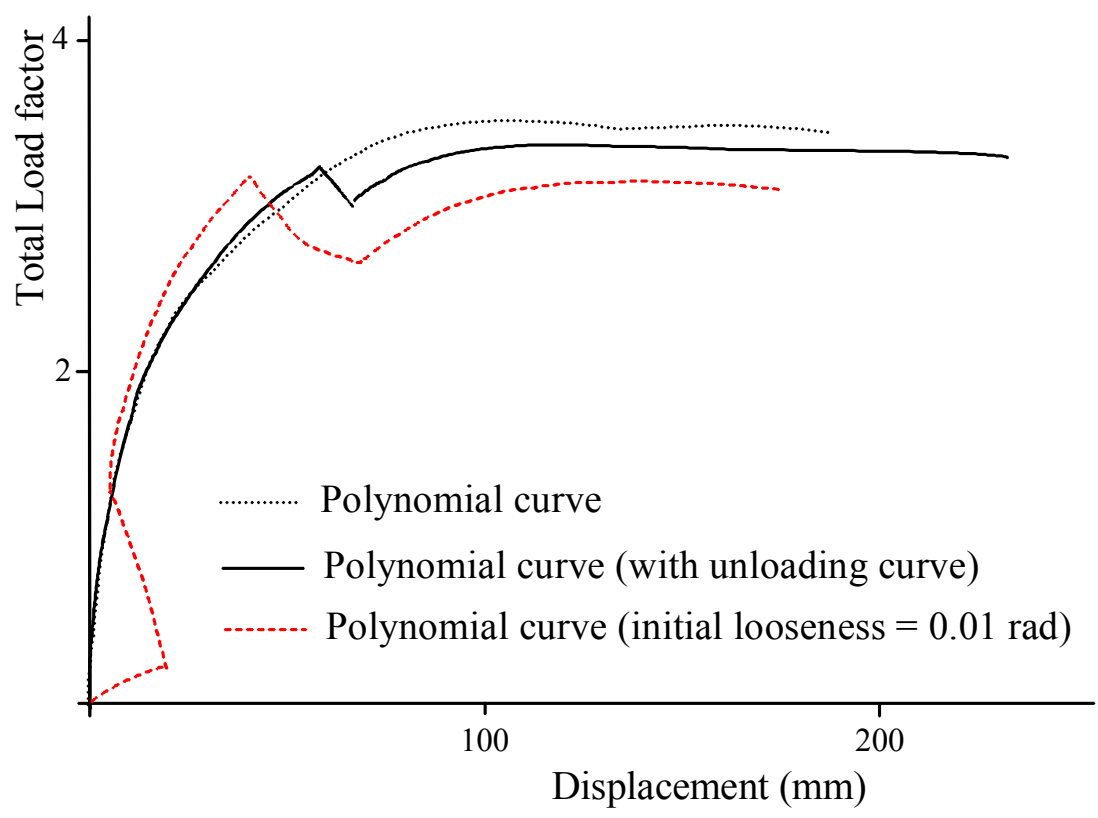

(a) Load- horizontal displacement curve of joint $J 2$

Fig. 16. Effects of initial looseness on frame 


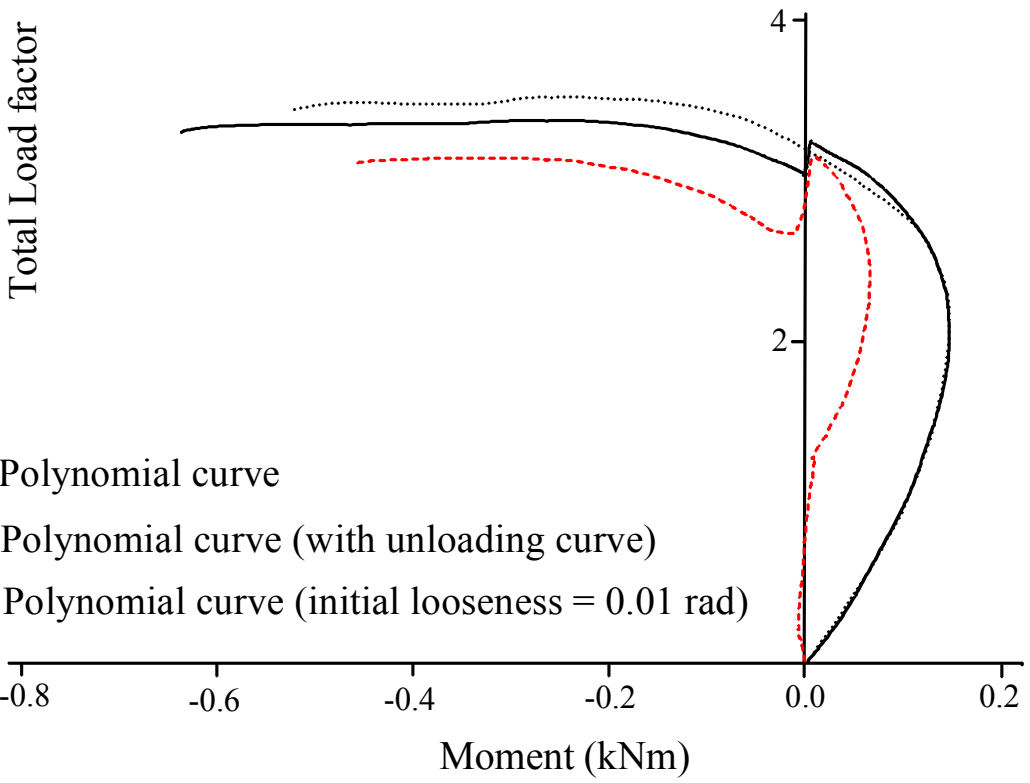

(b) Load-moment at joint $J 2$

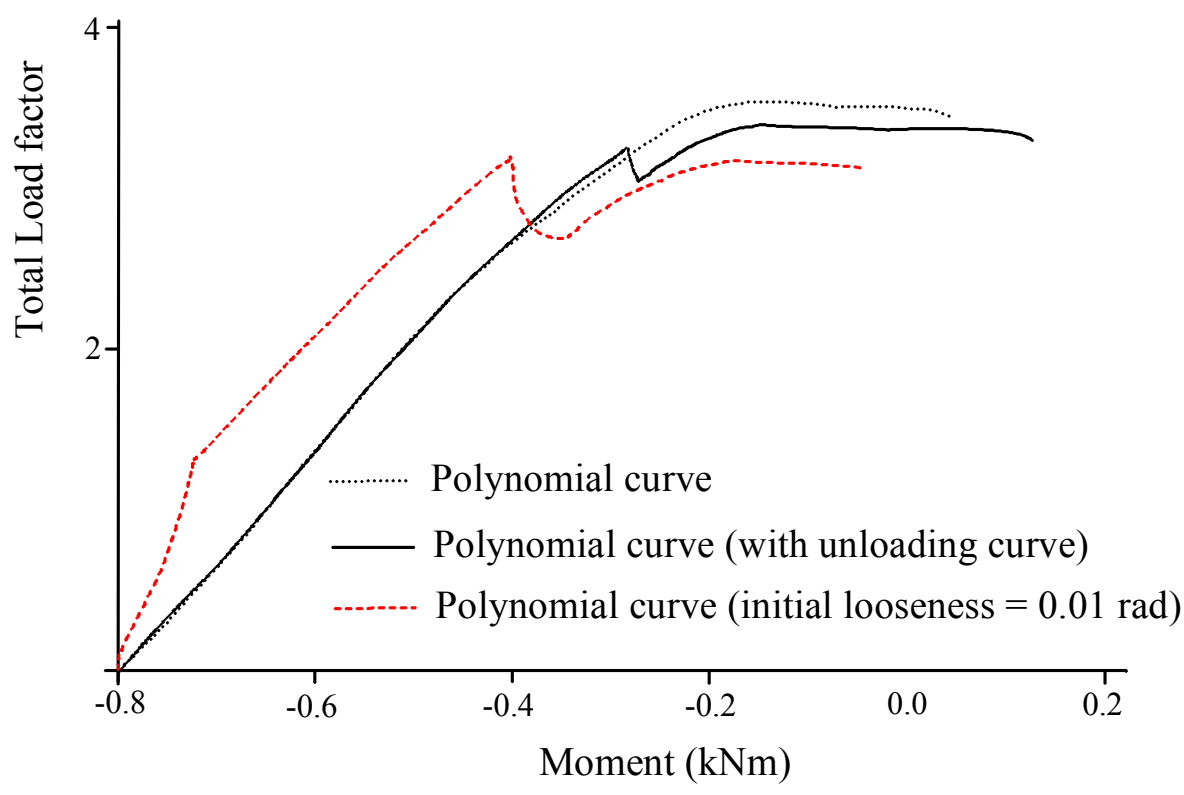

(c) Load-moment at joint $J 3$

Fig. 16. Effects of initial looseness on frame (continued)

When the load was applied, the frame took an out of plumb position which was approximately equal to 0.01 radian. At this stage both joints had a stiffness of $1 \mathrm{kNm} / \mathrm{rad}$. As the load increased, the right joint locked up causing the frame to deflect backwards. This creates an anomaly as there is apparent negative work being done on the structure despite the horizontal load pushing the structure in forward direction. This was because the work done by the vertical load in displacing the frame backward was greater than 
the work done by the horizontal force. This explains the first kink in the load displacement curve. The second kink corresponds to the load at which the left joint locked up, resulting in the frame deflecting forward. It was observed that the presence of initial looseness in the connection reduced the maximum load by about $13 \%$. The moments in the joints were relatively low when compared to the connections without initial looseness. The maximum load was reached before the joints reached their maximum moment capacity.

\subsection{One bay braced frame}

To determine the effects of bracing a bar element of area $0.000289 \mathrm{~m}^{2}$ was inserted between joint $\mathrm{J} 2$ and $\mathrm{J} 4$ as seen in Fig. 17.

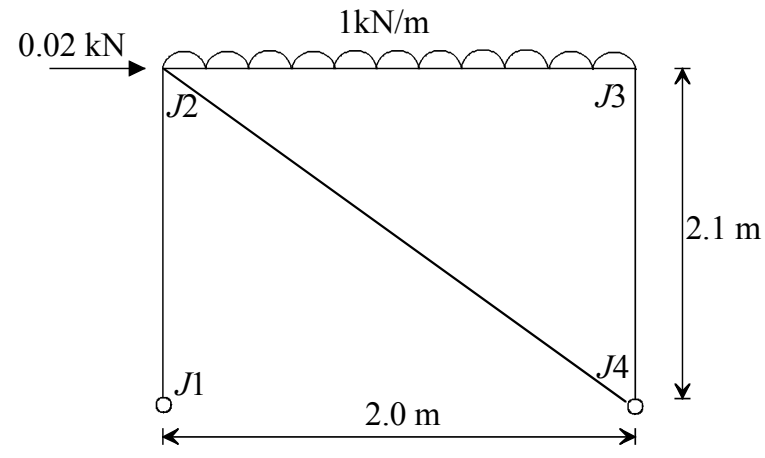

Fig. 17. Braced frame

Before looseness was added the resulting curves are given in Fig. 18.

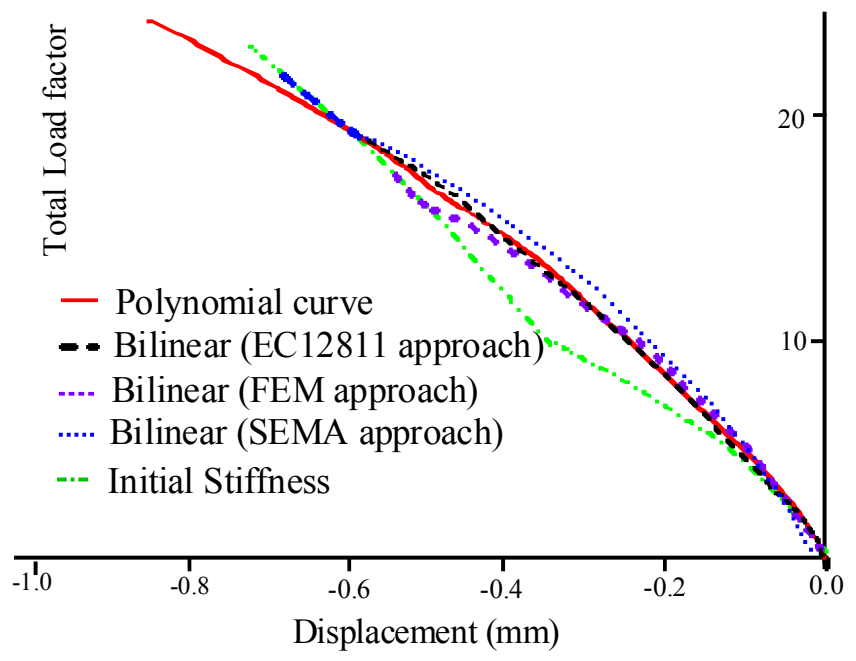

(a) Load- horizontal displacement curve of joint $J 2$

Fig. 18. Load against displacement and moments for frame 2 


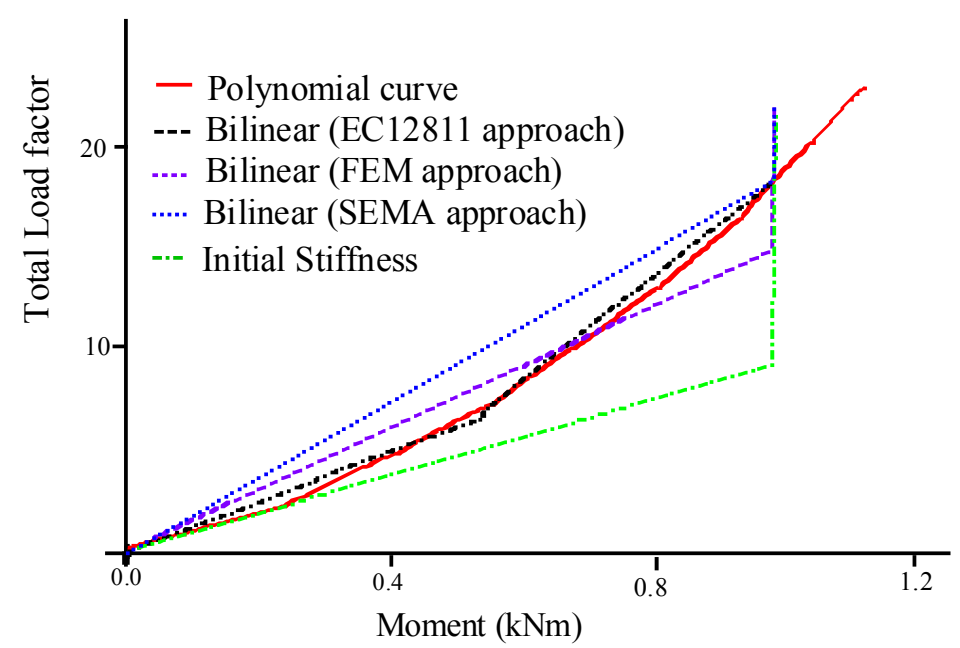

(b) Load-moment at joint $J 2$

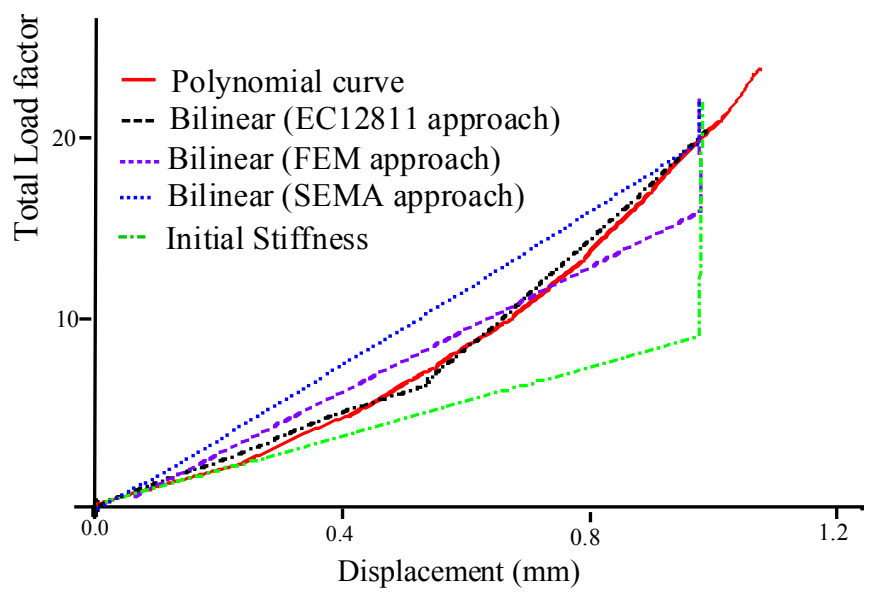

(c) Load-moment at joint $J 3$

Fig. 18. Load against displacement and moments for frame 2 (continued)

As can be seen the effect of bracing is to remove the unloading paths from the frame's behaviour under the given loading and hence all models, with the exception of the bilinear model predict similar paths. As there was little difference between the various models looseness was only considered for the polynomial model and the analysis repeated with highter loads so that unloading occurred. A comparison of the loadmoment and load-displacement curves is shown in Fig. 19.

From Fig. 19 it can be seen that for a braced frame with joints which unload bracing reduces the effects of looseness. 


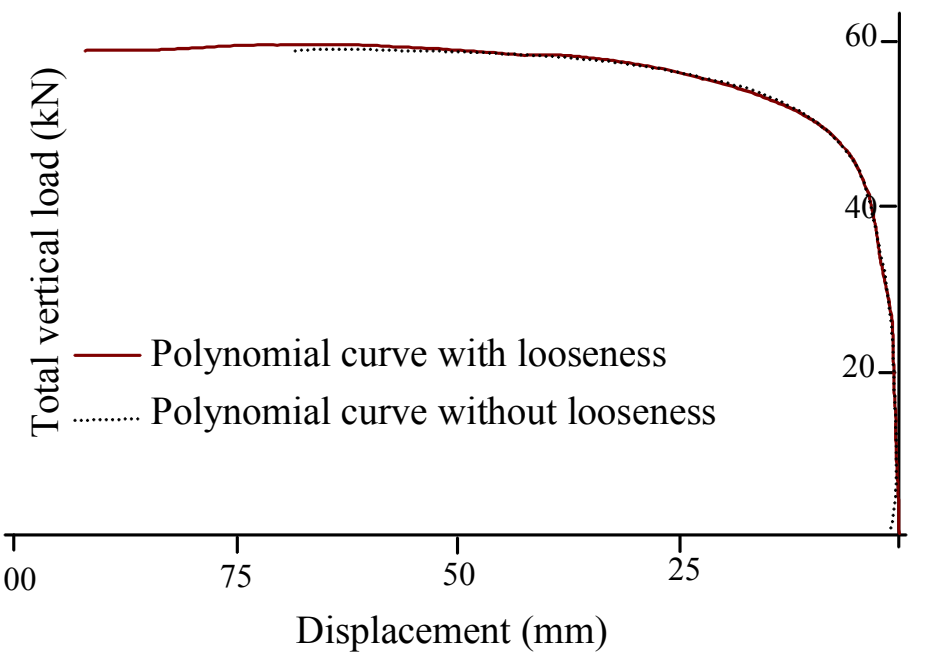

(a) Load- horizontal displacement curve of joint $J 2$

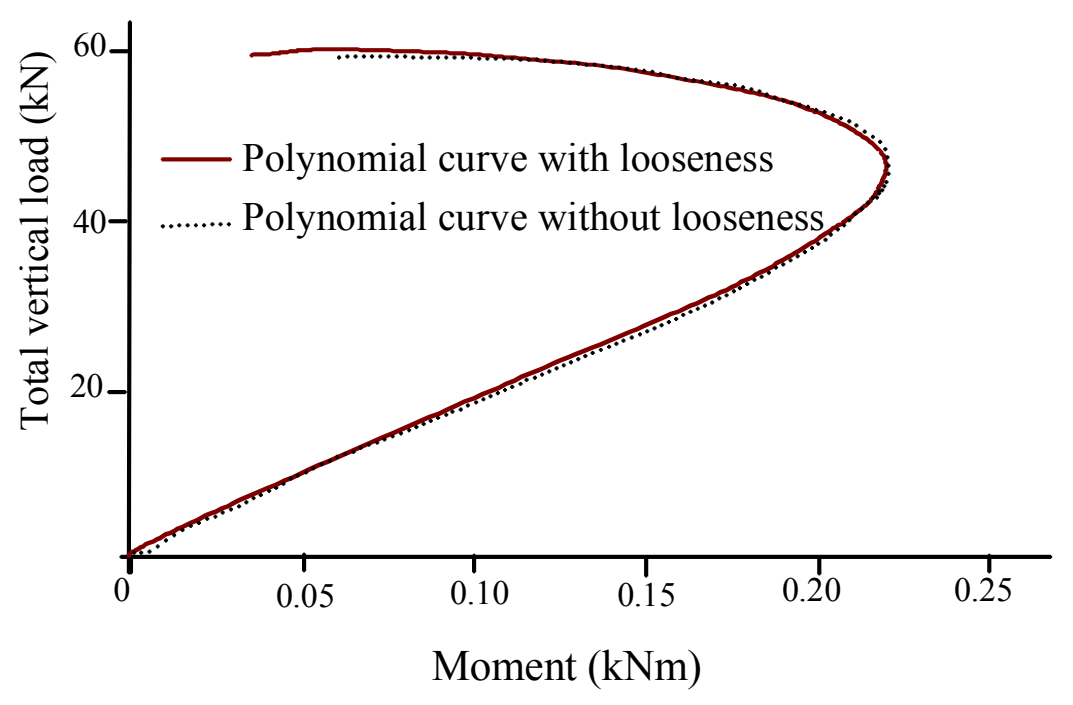

(b) Load-moment at joint $J 2$

Fig. 19. Load against displacement and moments including looseness for frame 2 


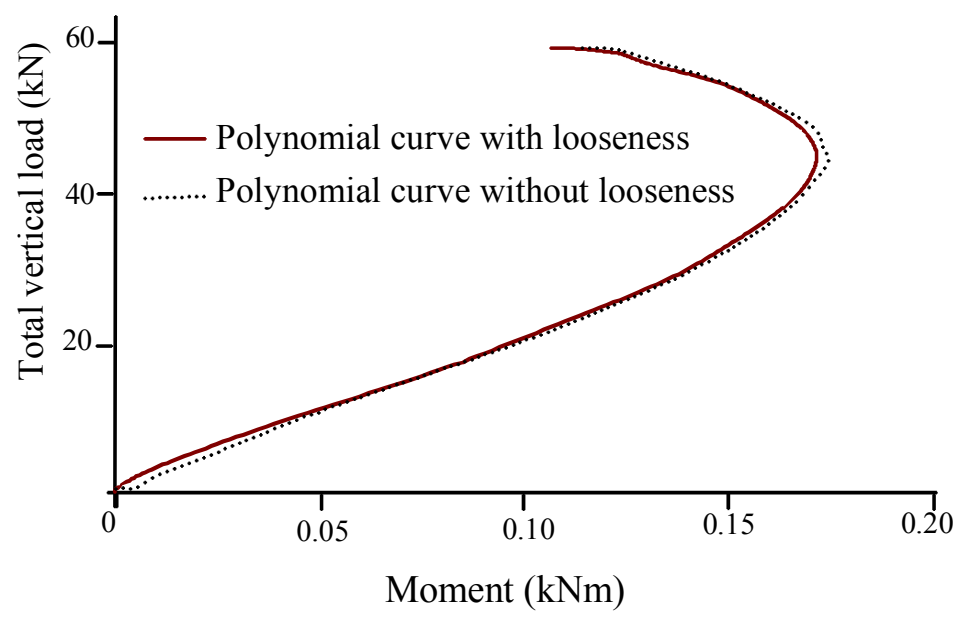

(c) Load-moment at joint $J 3$

Fig. 19. Load against displacement and moments including looseness for frame 2 (continued)

\subsection{Five bay, five storey frames}

To see if the conclusions from the sample frames were applicable to frames more typical of scaffold structures two five bay frames were analysed, one without bracing which is typical of the structures used to model the rear frame of an access scaffold and one with a common front face bracing pattern used in the UK [7,16]. All the elements were considered to be made from standard circular tubes with area $557 \mathrm{~mm}^{2}$ and second moment of area $138000 \mathrm{~mm}^{4}$. Fig. 20 shows the two frames.

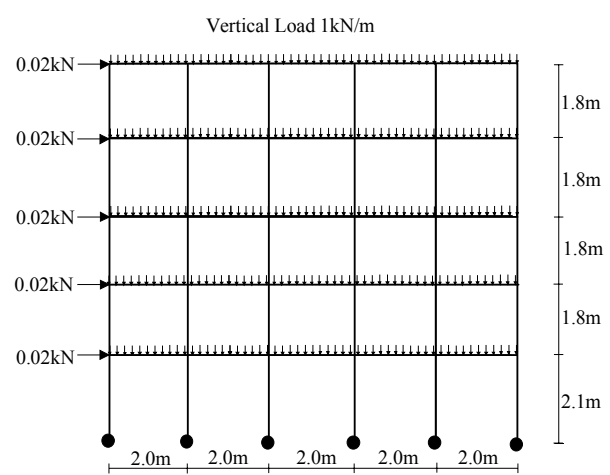

(a) Unbraced frame

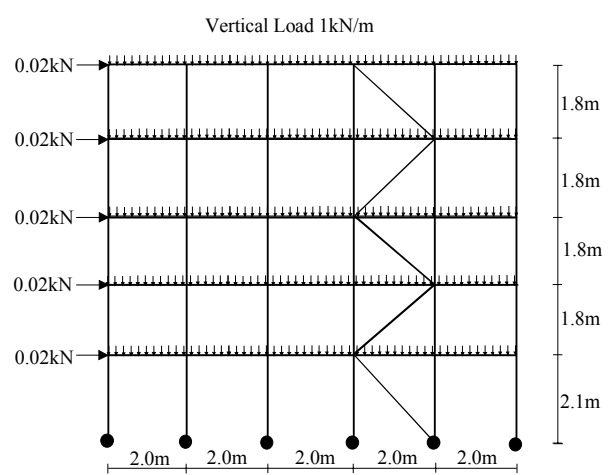

(b) braced frame

Fig. 20: Five bay scaffold frames

The lowest buckling mode of each frame (under vertical loading) was found using the LUSAS finite element package [27] and are given in Fig. 21. The stiffness of the joints for this analysis was taken to be $7.82 \mathrm{kNm} / \mathrm{rad}$ as this was the stiffness of the bilinear model which had the lowest stiffness. There was no looseness in the models. For this 
stiffness the unbraced frame buckles in a sidesway mode whilst the braced frame has a local buckle of one of the braced standards. The buckling on the two frames was respectively $31.9 \mathrm{kN}$ and $453.5 \mathrm{kN}$.
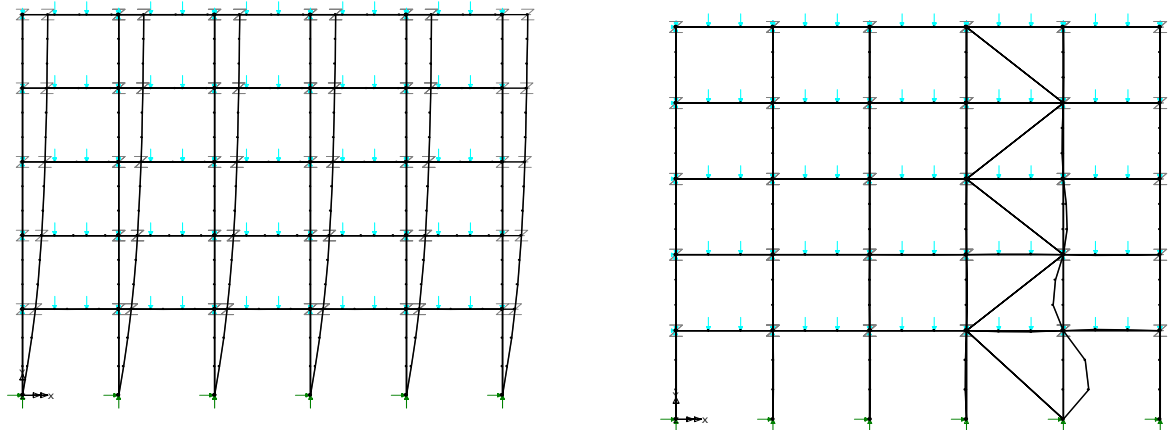

Fig. 21: Lowest buckling mode of unbraced and braced frames

To determine the maximum capacity of the unbraced frame a dead load of $30 \%$ of the buckling load was applied to simulate a combination of dead weight and superimposed vertical live load. In order to simulate the action of wind the horizontal side load was proportionally increased until failure of the structure occurred (when all the members of the first level reached the failure moment and hence formed a mechanism). The maximum moment of the connections for all models was taken to be $0.97 \mathrm{kNm}$. Table 3 shows the maximum horizontal loads and horizontal deflection of the top lift achieved for the different connection models.

Table 3: Maximum horizontal load for the sway frame

\section{Connection Model Horizontal Load (kN) Displacement (m)}

$\begin{array}{lll}\text { Polynomial curve } & 0.72 & 0.782 \\ \text { Eurocode } & 0.72 & 0.782 \\ \text { FEM } & 0.68 & 0.698 \\ \text { Bilinear curve } & 0.67 & 0.894 \\ \text { Initial Stiffness } & 0.67 & 0.363\end{array}$

The Eurocode and the Polynomial curve gave the same results throughout the range. The Federation Europeéne de la Manutention approach gave results closer to the polynomial curve than either of the other two bilinear models. When an initial connection looseness of 0.01 radians was applied to all connections the polynomial model predicted an initial sidesway of $200 \mathrm{~mm}$ at the top when all the connections locked up. The maximum capacity of the frame was unaltered but the horizontal deflection at failure was approximately 14\% higher for the 'loose' frame. If horizontal deflections were limited to $5 \%$ of the frame height there was a reduction in load capacity of approximately $20 \%$.

An alternative analysis for the frame was taken where the horizontal and vertical loads were increased proportionally. The load displacement curve for the top lift is given in 
Fig. 22 for the stiffness modelled by the polynomial curve. The ultimate load capacity of the frame was reduced by approximately $8 \%$ when looseness was considered.

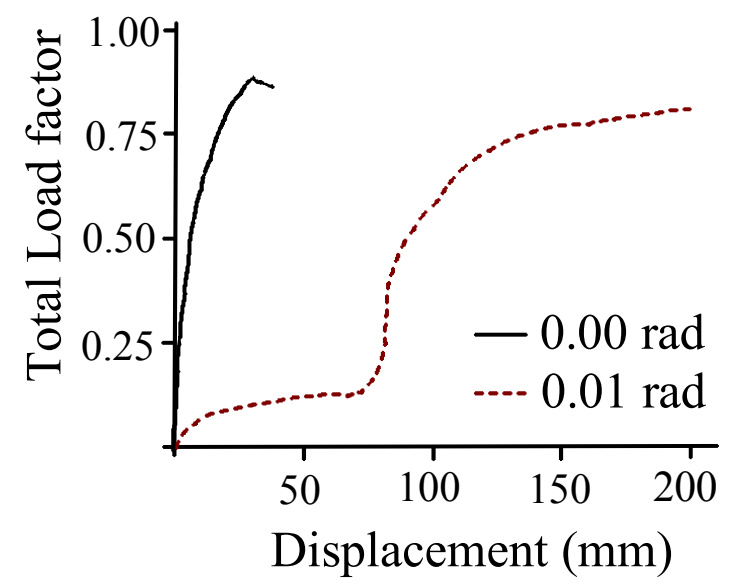

Fig. 22: Load-displacement curve for top left element under proportional loading

Table 4 shows the results of applying the analysis to the braced five storey frame. In this case the vertical load applied was $50 \%$ of the buckling load of the frame and horizontal loads were then increased until failure. The axial force is given for the member which buckled at the lowest buckling mode and the horizontal displacement at the top left joint at the maximum horizontal load. In the absence of test data the results corresponding to the polynomial curve model were considered as a benchmark for the comparison of other connection models. The variation in the maximum horizontal load predicted by other connection models was found to be within $\pm 8 \%$ of polynomial curve model. As expected, the initial stiffness model gave the maximum horizontal load whilst the bilinear connection model gave the lowest value. The Eurocode and Federation Europeéne de la Manutention based connection models gave results very close to the more accurate polynomial curve model. However, the variation in the maximum axial load in the member predicted by the various models was within $\pm 3 \%$ indicating that for large braced frames the different approximations of the $M-\theta$ curve did not make significant difference. It was also observed that the maximum load carried by the frame was influenced by the bracing arrangement. If the direction of the horizontal load is reversed, then the other upright in the braced bay is subjected to maximum compressive force and hence will fail first.

Table 4: Maximum horizontal load for the braced frame

$\begin{array}{lccc}\text { Connection Model } & \begin{array}{c}\text { Maximum Axial } \\ \text { Load (kN) }\end{array} & \begin{array}{c}\text { Horizontal Load } \\ (\mathbf{k N})\end{array} & \begin{array}{c}\text { Displacement } \\ (\mathbf{m m})\end{array} \\ \text { Polynomial curve } & 95.8 & 5.01 & \\ \text { Eurocode } & 94.9 & 4.95 & 25.8 \\ \text { FEM } & 95.3 & 5.00 & 24.1 \\ \text { Bilinear curve } & 93.1 & 4.75 & 23.9 \\ \text { Initial Stiffness } & 98.9 & 5.45 & 22.8 \\ \end{array}$


In order to study the effects of initial rotational looseness in the joints, the analysis was repeated by including a looseness of \pm 0.01 radian in the connections. For this study the polynomial curve model was used. Looseness was included by adding a linear curve of stiffness $1 \mathrm{kNm} / \mathrm{rad}$ to the polynomial curve model below a moment of $0.01 \mathrm{kNm}$. The analysis was carried out for three values of vertical load $-5 \mathrm{kN} / \mathrm{m}, 3 \mathrm{kN} / \mathrm{m}$ and $1 \mathrm{kN} / \mathrm{m}$. Table 5 shows a comparison of results corresponding to no rotational looseness and an initial rotational looseness of \pm 0.01 radian.

Table 5: Maximum loads and displacement for the braced frame with/without looseness

Description

Rotational joint
Looseness/
Max

Axial Load (kN)

Horizontal Load (kN)

Displacement (mm)

\author{
Vertical Load \\ $(5 \mathrm{kN} / \mathrm{m})$
}

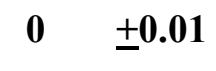

$\begin{array}{ll}95.8 & 88.4\end{array}$

$5.01 \quad 4.20$

$25.8 \quad 27.8$

\author{
Vertical Load \\ $(3 \mathrm{kN} / \mathrm{m})$
}

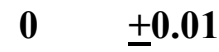

$\begin{array}{ll}96.8 & 88.9\end{array}$

$7.45 \quad 6.55$

$30.1 \quad 27.6$

\author{
Vertical Load \\ (1 kN/m)
}

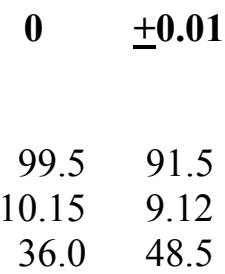

The looseness in the joints resulted in the frame taking up an out of plumb position before the connections locked up. There was a reduction in the maximum horizontal load. This was because of the initial rotational looseness in the joints and the P- $\Delta$ effect resulting from the constant vertical load. The effect reduced with decreased in the vertical loads. However, irrespective of the vertical load, the maximum load in the braced upright decreased by approximately $8 \%$.

A second analysis was undertaken when both vertical loads and horizontal loads were increased proportionally. In this case the initial connection looseness had no effect on the maximum load or on the horizontal displacements.

From these two sets of analyses it can be seen that connection looseness can significantly reduce the maximum load carrying capacity of braced frames when lateral loads such as wind loads are predominant.

\subsection{Design considerations with looseness}

From the analyses undertaken in Section 3.3 on the five bay, five storey frames in Sections 3.2 and 3.3 it can be seen that the maximum load capacity under proportionally increasing horizontal and vertical loads for braced frames with connections exhibiting looseness does not change significantly and hence looseness need not be included in the analysis for this case of loading. However for frames subjected to varying side loads there is a reduction in maximum load capacity. To get a design procedure the following analyses were undertaken: 
(i) The looseness was included in the $M-\theta$ curve as discussed in Section 2.2.8 and models constructed using the Polynomial approach and the Federation Europeéne de la Manutention (FEM) method (in this case the curve was replaced by a bilinear model with a stiffness $1 \mathrm{kNm} / \mathrm{rad}$ for a moment below $0.01 \mathrm{kNm}$ and a stiffness $10.65 \mathrm{kNm} / \mathrm{rad}$ above $0.01 \mathrm{kNm}$ ).

(ii) The studies conducted in Section 3 indicated that when looseness is present in the connection, frame takes up an out of plumb position. Therefore, the looseness was included by adding an out of plumb angle of 0.02 radians to the frame and the original models without looseness used. The angle 0.02 radians was chosen as this is twice the maximum looseness observed in the tested connections. It could be different for other scaffolds.

Table 6 gives the results of the two analyses where the axial load is given on the buckled element in Fig.21 and displacement on the element in the top left position.

Table 6: Design results for braced frame

$\begin{array}{llccc}\begin{array}{l}\text { Connection } \\ \text { Model }\end{array} & \text { Design model } & \begin{array}{l}\text { Max axial } \\ \text { load (kN) }\end{array} & \begin{array}{l}\text { Max Disp } \\ (\mathbf{m m})\end{array} & \begin{array}{l}\text { Max Horizontal } \\ (\mathbf{k N})\end{array} \\ \begin{array}{l}\text { Polynomial } \\ \text { curve }\end{array} & \text { Polynomial curve } & 88.4 & 27.8 & 4.20 \\ \begin{array}{l}\text { Polynomial } \\ \text { curve }\end{array} & \begin{array}{l}\text { Geometric } \\ \text { Imperfection }\end{array} & 95.5 & 25.4 & 4.00 \\ \text { FEM } & \begin{array}{l}\text { FEM approximation } \\ \text { FEM }\end{array} & 89.0 & 47.7 & 3.96 \\ & \begin{array}{l}\text { Geometric } \\ \text { Imperfection }\end{array} & 94.5 & 23.2 & 3.90\end{array}$

It can be seen that all three approximate models (both Federation Europeéne de la Manutention (FEM) approach and the use of the Geometric imperfection in the Polynomial curve) gave conservative estimates of the maximum horizontal or side load that the frames could take, assuming that the full Polynomial curve is considered to be the 'exact' solution. The maximum axial loads for the approximate models were also conservative. However, the maximum displacements obtained using geometric imperfections was slightly on the low side (maximum error 16\%). The authors therefore recommend that the Federation Europeéne de la Manutention approach with the geometric imperfection be used as this is the simplest safe model as displacements are not usually critical in scaffold analyses.

\subsection{Conclusions}

This paper has presented an algorithm to completely model the behaviour of scaffold connections which is able to correctly follow not only a nonlinear loading path but also the unloading path. Because of the geometry of the connections plasticity takes place at 
low loads and hence the unloading path is different to the loading path. The algorithm is also able to model regions of the curve where looseness is predominant.

The algorithm is applied to several alternative procedures commonly used to model load paths and shows that the initial stiffness approach leads to results which will lead to unconservative predictions of maximum load. A bilinear model using the SEMA approach would appear to be conservative as using a low rotational stiffness produces large deflections and low predictions of maximum capacity. The Federation Europeéne de la Manutention approach (a simple bilinear model), a polynomial curve fit and the Eurocode approach (a trilinear model) yield results of similar magnitudes.

The various models are used to analyse simple frames where it is shown that for sway frames looseness makes the frame unstable but for the braced frame analysed looseness had little effect on the result.

Finally the authors recommend a simple bilinear model based on the Federation Europeéne de la Manutention approach together with a geometric imperfection of twice the looseness observed in the connection but further research is required to test this assumption for different types of scaffold.

\section{References}

[1] Chen WF, Lui EM. Stability Design of Steel Frames. London: CRC Press, 1991.

[2] Godley MHR, Beale RG. Analysis of large proprietary access scaffold structures. Proceedings of the Institution of Civil Engineers - Structures \& Buildings, 146(1):31-39, 2001.

[3] Beale RG, Abdel-Jaber MS, Godley MHR, Abdel-Jaber M. Rotational Strength and Stiffness of Tube and Fitting Scaffold Couplers., Report, Department of Mechanical Engineering, Oxford Brookes University, UK, 2008.

[4] Abdel-Jaber MS, Beale RG, Godley MHR, Abdel-Jaber M. Rotational resistances of tube and fitting scaffold connectors. Proceedings of the Institution of Civil Engineers - Structures \& Buildings, 162(6):391-404, 2009.

[5] Prabhakaran U, Nonlinear Analysis of Scaffolds with Semi rigid Connections, PhD Thesis, Oxford Brookes University, UK, 2009.

[6] Beale RG, Godley MHR. The analysis of scaffold structures using LUSAS. In: Bigwood D, Editor. Proceedings of LUSAS 95. London; FEA Ltd; 9-16, 1995.

[7] Chan SL, Zhou ZH, Chen WF, Peng JL, Pan AD. Stability analysis of semi-rigid steel scaffolding. Engineering Structures, 18(3):568-574, 1995.

[8] Godley MHR, Beale RG. Sway stiffness of scaffold structures. The Structural Engineer, 75(1): 4-12, 1997.

[9] Huang YL, Kao YG, Rosowsky DV. Load carrying capacities and failure modes of scaffold shoring systems, Part II: An analytical model and its closed form solution. Structural Engineering and Mechanics, 10(1):67-79, 2000.

[10] Milojkovic B, Beale RG, Godley MHR .Modelling Scaffold Connections. Proceedings of the Fourth ACME UK Annual Conference, Glasgow, 85-88, 1996.

[11] Peng JL, Pan AD, Rosowsky DV, Chen WF, Yen T, Chan SL. High clearance scaffold systems during construction-I. Structural modelling and modes of failure. Engineering Structures, 18(3):247-257, 1996. 
[12] Weesner LB, Jones HL. Experimental and analytical capacity of frame scaffolding. Engineering Structures, 23(6):592-599, 2001.

[13] Beale RG. Review of Research into Scaffold Structures. Civil Engineering Computations: Tools and Techniques, Saxe-Coburg Publications, Topping BVH Editor, Ch 12, 271-300, 2007.

[14] Ramanathan M. Hong Kong - bastion of bamboo scaffolding. Proceedings of the Institution of Civil Engineers - Civil Engineering, 161(4):177-183, 2008.

[15] Peng JL, Chen KH, Chan SL, Chen WT. Experimental and analytical studies on steel scaffolds under eccentric loads. Journal of Constructional Steel Research, 65(2): 422-435, 2009.

[16] Liu, HB, Zhao, QH, Wang XD, Zhou t, Wang D, Liu J, Chen ZH. Experimental and analytical studies on the stability of structural steel tube and coupler scaffolds without X-bracing. Engineering Structures, 32(4):1003-1015, 2010.

[17] Beale RG, Godley MHR. Numerical Modelling of Tube and Fitting Access Scaffold Systems. Advanced Steel Construction, 2(3):199-223, 2006.

[18] British Standards Institute. EN 12811-3, Temporary works equipment, Part 3: Load Testing. London, 2002.

[19] British Standards Institution,. EN74-1:2005, Couplers, spigot pins and base-plates for use in falsework and scaffolds - Part 1: Couplers for tubes - requirements and test procedures. London, 2005.

[20] British Standards Institute. EN 12810-2, Façade scaffolds made of prefabricated components - Part 2: Particular methods of structural design. London, 2003.

[21] Federation Europeéne de la Manutention. FEM 10.2.02, The design of static steel pallet racking, Section X of the Equipement et Proceeds de Stockage. Manchester, 2000.

[22] British Standards Institution. EN15512, Steel static storage systems - Adjustable pallet racking systems - principles for structural design. London, 2009.

[23] Abdel-Jaber MS, Beale RG, Godley MHR. Numerical Study on Semi-Rigid Racking Frames under sway. Computers and Structures, 83(28-30), 2463-2475, 2005.

[24] Abdel-Jaber MS, Beale RG, Godley MRG. A theoretical and experimental investigation of pallet rack structures under sway. Journal of Constructional Steel Research, 62(1/2):68-80, 2006.

[25] Abdel-Jaber MS, Beale RG, Abdel-Jaber M, Shatnawi AM. Two-dimensional and three-dimensional comparison of second order analysis of pallet rack structures with non-linear moment-curvature for semi-rigid connections. In: Mahendron M, editor. Proceedings of the Fifth International Conference on Thin-walled Structures, Recent Innovations and Developments (ICTWS 2008). Brisbane, 323330, 2008.

[26] SEMA. Code of practice for static racking. The storage equipment manufacturers association, UK Trade Association, 1985.

[27] LUSAS 14.0, FEA Ltd, London UK, 2009. 